\title{
Tropopause referenced ozone climatology and inter-annual variability (1994-2003) from the MOZAIC programme
}

\author{
V. Thouret ${ }^{1}$, J.-P. Cammas ${ }^{1}$, B. Sauvage ${ }^{1}$, G. Athier ${ }^{1}$, R. Zbinden ${ }^{1}$, P. Nédélec ${ }^{1}$, P. Simon ${ }^{2}$, and F. Karcher ${ }^{2}$ \\ ${ }^{1}$ Laboratoire d'Aérologie, UMR 5560, Université Paul Sabatier, Toulouse, France \\ ${ }^{2}$ CNRM, Météo-France, Toulouse, France
}

Received: 21 February 2005 - Published in Atmos. Chem. Phys. Discuss.: 29 July 2005

Revised: 20 October 2005 - Accepted: 20 December 2005 - Published: 31 March 2006

\begin{abstract}
The MOZAIC programme collects ozone and water vapour data using automatic equipment installed on board five long-range Airbus A340 aircraft flying regularly all over the world since August 1994. Those measurements made between September 1994 and August 1996 allowed the first accurate ozone climatology at 9-12 km altitude to be generated. The seasonal variability of the tropopause height has always provided a problem when constructing climatologies in this region. To remove any signal from the seasonal and synoptic scale variability in tropopause height we have chosen in this further study of these and subsequent data to reference our climatology to the altitude of the tropopause. We define the tropopause as a mixing zone $30 \mathrm{hPa}$ thick across the 2 pvu potential vorticity surface. A new ozone climatology is now available for levels characteristic of the upper troposphere (UT) and the lower stratosphere (LS) regardless of the seasonal variations of the tropopause over the period 19942003. Moreover, this new presentation has allowed an estimation of the monthly mean climatological ozone concentration at the tropopause showing a sine seasonal variation with a maximum in May (120 ppbv) and a minimum in November ( 65 ppbv). Besides, we present a first assessment of the inter-annual variability of ozone in this particular critical region. The overall increase in the UTLS is about $1 \% / \mathrm{yr}$ for the 9 years sampled. However, enhanced concentrations about 10-15\% higher than the other years were recorded in 1998 and 1999 in both the UT and the LS. This so-called "19981999 anomaly" may be attributed to a combination of different processes involving large scale modes of atmospheric variability, circulation features and local or global pollution, but the most dominant one seems to involve the variability of the North Atlantic Oscillation (NAO) as we find a strong positive correlation (above 0.60 ) between ozone recorded in the upper troposphere and the NAO index. A strong anti-
\end{abstract}

Correspondence to: V. Thouret

(thov@aero.obs-mip.fr) correlation is also found between ozone and the extremes of the Northern Annular Mode (NAM) index, attributing the lower stratospheric variability to dynamical anomalies. Finally this analysis highlights the coupling between the troposphere, at least the upper one, and the stratosphere, at least the lower one.

\section{Introduction}

The MOZAIC programme was designed to collect ozone and water vapor data, using automatic equipment installed on board five long-range Airbus A340 aircraft flying regularly all over the world since August 1994 (Marenco et al., 1998). For recent details, see the web site http://www.aero. obs-mip.fr/mozaic/. The overall objective of the programme is to improve our physical and chemical understanding of the atmosphere. Specifically we aim to evaluate the impact of aircraft and other anthropogenic emissions and to provide extensive validation of chemistry transport models (CTMs). From data recorded at cruise levels during a two years period (September 1994 to August 1996), the first accurate ozone climatology at 9-12 km altitude was generated (Thouret et al., 1998a). The climatology based on these high quality data had been compared to the climatology found using the ozone soundings network and the comparisons were very good (Thouret et al., 1998b). Thus MOZAIC and the sondes network complement each other. The MOZAIC data have been used for chemical model validation either globally (Law et al., 1998, 2000; Emmons et al., 2000) or for regional analyses concerning regions never previously sampled such as the Middle East (Li et al., 2001) or West Africa (Martin et al., 2002; Sauvage et al., 2005). The MOZAIC network provides a dataset densely and regularly distributed in the upper troposphere and lower stratosphere region (UTLS) with useful constraints for studies of stratosphere-troposphere exchange (STE) in both mid-northern latitudes (Gouget et al., 2000)

Published by Copernicus GmbH on behalf of the European Geosciences Union. 
Table 1. Coordinates of the three selected regions over the NAFC, global average over the sampling period and inter-annual variability in the UT and in the LS calculated between August 1994 and December 2003.

\begin{tabular}{lccc}
\hline & $\begin{array}{c}\text { Global average } \\
\text { (in ppb) UT/LS }\end{array}$ & $\begin{array}{c}\text { Increase rate } \\
\text { in the UT }\end{array}$ & $\begin{array}{c}\text { Increase rate } \\
\text { in the LS }\end{array}$ \\
\hline $\begin{array}{l}\text { Eastern US } \\
\left(3550^{\circ} \mathrm{N},-90-60^{\circ} \mathrm{W}\right)\end{array}$ & $62.9 / 292.1$ & $0.99+/-0.82 \% / \mathrm{yr}$ & $0.80+/-1.06 \% / \mathrm{yr}$ \\
$\begin{array}{l}\text { Europe } \\
\left(3550^{\circ} \mathrm{N},-300^{\circ} \mathrm{W}\right)\end{array}$ & $59.6 / 286.1$ & $1.00+/-0.90 \% / \mathrm{yr}$ & $1.99+/-1.21 \% / \mathrm{yr}$ \\
$\begin{array}{l}\text { Iceland } \\
\left(5570^{\circ} \mathrm{N},-60-10^{\circ} \mathrm{W}\right)\end{array}$ & $58.8 / 328.1$ & $1.12+/-0.86 \% / \mathrm{yr}$ & $1.54+/-1.37 \% / \mathrm{yr}$ \\
\hline
\end{tabular}

and southern subtropical latitudes (Scott et al., 2001). One of the major issue when dealing with ozone data in the UTLS is to be able to identify the different sources and to discriminate correctly the two components corresponding to the two "reservoirs", i.e. the troposphere and the stratosphere. Several recent studies have been made trying to resolve the problem of the tropospheric and stratospheric sources of ozone in the upper troposphere. One of them used the potential vorticity analyses to rebuild the wintertime MOZAIC ozone climatology on an equivalent latitude scale (Morgenstern and Marenco, 2000) and show that the greatest ozone concentrations occur most frequently in the vicinity of the NorthAtlantic storm track. Stohl et al. (2001) proposed an extension of MOZAIC climatologies using trajectory statistics to better investigate the different sources of ozone observed at altitudes sampled by aircraft. In this work we go a step further. We have chosen to use the potential vorticity (PV) based tropopause against which to reference all altitudes. Therefore we will obtain the ozone distributions in both the upper troposphere (UT) and the lower stratosphere (LS) regardless of the seasonal variations of the tropopause height. Moreover, we notably avoid using any ozone threshold to separate the two components as has been used previously. For example, Thouret et al. (1998a) used a 100 ppbv threshold to separate tropospheric and stratospheric ozone. We believe it to be more rigorous to use a criterion completely independent of the ozone vertical distribution. Taking this approach leads us to consider two problems. What is the "best" tropopause definition and how do we define the number and thickness of the vertical levels used to classify the regions above and below the tropopause? We need to consider the varying definitions of the tropopause (see Sect. 4), and the fact that these definitions lead to a substantial difference in altitude. Furthermore, many studies have started considering the tropopause as a mixing or transition zone (Fischer et al., 2000; Brunner et al., 2001; Hoor et al., 2004) rather than a barrier acting at a single altitude. Being able to refer the data to the tropopause altitude first implies to be able to define the tropopause effectively. In Sect. 4, we will give an overview of the different definitions of the tropopause used up to now.
The ozone horizontal and vertical distributions will be presented in Sect. 5. Within the last decade, the UTLS region has been identified as a crucial zone for both climate issues and ozone budget analyses. MOZAIC is the only programme providing such high quality data over this region for almost 10 years. The assessment of the inter-annual variability of ozone in the UTLS (presented in Sect. 6 and discussed in Sect. 7) is one of the most interesting opportunities provided by the multi-year MOZAIC dataset. It should further give specific constraints to ozone budget studies. In this paper, we propose a first stage of investigation essentially leading to the characterization of the so-called "1998-1999 anomaly". Measurements made during 1998 and 1999 exhibit anomalously high ozone concentrations throughout the UTLS. We propose a discussion of the different possible causes.

\section{The MOZAIC data used in this study}

We are using all the MOZAIC measurements recorded from August 1994 to December 2003; i.e. a data set of 19,185 flights regularly sampling the different seasons. For a better statistical significance we have decided to focus only on the region corresponding to the North Atlantic Flight Corridor (NAFC) and the adjacent continents (Europe and North Eastern US) because that is the region where the frequency of the measurements is the most intensive (at least two flights a day). For the purpose of our inter-annual variability analysis we have selected three regions within the NAFC named hereafter Europe, Eastern US and Iceland. Coordinates are given in Table 1. They have been chosen to match the regions where Appenzeller et al. (2000) calculate a strong correlation between the tropopause altitude and the North Atlantic Oscillation index. Further details will be given in Sect. 6 . To ensure that long-term series are free of instrumental artefact measurement quality control procedures have been performed and have remained unchanged since the beginning of the programme in 1994. The MOZAIC ozone analysers are dual-beam UV absorption Model 49-103 from Thermo Environment Instruments, USA. Their performance and installation are completely described in Thouret et al. (1998). 
The instruments are laboratory calibrated before and after the flight periods, whose duration is generally 12 to 18 months. The laboratory calibration is performed with a reference analyser periodically cross-checked with a National Institute of Standards and Technology in France. Additionally and during the flight operation period, each instrument is checked every flight for the zero and for the calibration factor, using a built-in ozone generator. Finally, intercomparisons are made between aircraft when they fly close in location and time, which happens several times a month and guarantees the permanence of the analysers specifications: $\pm 2 \mathrm{ppbv}, \pm 2 \%$.

\section{The Potential Vorticity along each MOZAIC flight trajectory}

The computation of potential vorticity (PV) along MOZAIC aircraft pathways is done in two steps: first, computation of PV on the ECMWF model grid, then interpolation to the aircraft trajectories. For the first step, the maximum available resolution of ECMWF analysis was used; i.e. 61 levels on the vertical (from the surface up to $10 \mathrm{hPa}$ ) and T213 spectral truncation on the horizontal (corresponding to a $640 \times 320$ global grid; i.e. a grid size of approximately $60 \mathrm{~km}$ ). This was the maximum spatial resolution available at the beginning of the MOZAIC programme. For the second step, a 3-D cubic interpolation using Lagrange formulation is used for the interpolation in space, while a simple linear interpolation in time is used (ECMWF analysis are available every $6 \mathrm{~h}$, at 00:00, 06:00, 12:00 and 18:00 UT). In addition, the pressure levels of 4 iso-PV surfaces $(1.5,2,3$ and 4 pvu) are computed along MOZAIC aircraft pathways to locate the flight altitude on a vertical PV coordinate axis.

\section{The tropopause definition}

\subsection{Thermal, dynamical or chemical criteria?}

The most frequently used definitions of the tropopause rely upon thermal or dynamical constraints. The thermal tropopause is the lower boundary of a $2 \mathrm{~km}$ thick layer, in which the air temperature lapse rate is less than $2 \mathrm{~K} / \mathrm{km}$ (World Meteorological Organization, 1957). The dynamical tropopause is characterized by a sharp gradient in PV. The value commonly used to define the tropopause is $\mathrm{PV}=2 \mathrm{pvu}$. However, various studies imply a use of different values between 1.6 and 3.5 (e.g. Danielsen, 1968; Hoskins et al., 1985; Hoerling et al., 1991; Ovarlez et al., 1999). An alternative definition, the chemical one is often called the "ozone tropopause" and is based on three criteria of vertical gradient and ozone mixing ratio as explained in details by Bethan et al. (1996). We use the PV definition of the tropopause with parameters involving horizontal and vertical derivatives (vorticity and static stability, respectively) made available through the ECMWF analyses as previously described.

\subsection{The tropopause as a mixing zone}

The abrupt changes of atmospheric properties and concentrations of chemical species, observed near the tropopause, have classically suggested that it is a thin layer separating the stratosphere from the troposphere. However there is evidence to support the view that the tropopause is a transition zone (Hoerling et al., 1991; Hoinka, 1998). Recent studies have considered the tropopause as a third region between the UT and the LS. For example, Brunner et al. (2001) considered the region with PV values between 2 and 3 as a transition zone between the UT and the LS. Hoor et al. (2004) have discussed the presence of a mixing zone with a thickness between 20 and $40 \mathrm{~K}$ (corresponding to approximately 50 to $100 \mathrm{hPa}$ ) above the local tropopause (seen as ozone greater than $120 \mathrm{ppb}$ ). Fischer et al. (2000) considered a mixing zone with a thickness of 2-3 km above the local tropopause. Pan et al. (2004) statistically identified a transition layer centered on the thermal tropopause with aircraft measurements. Logan (1999) used the thermal definition of the tropopause but considered the UT $1 \mathrm{~km}$ below and the LS $2 \mathrm{~km}$ above the local tropopause. More over, each tropopause definition leads to a different height. Comparisons of tropopause heights derived from temperatures and from PV may be found in the studies of Hoerling et al. (1991) and Holton et al. (1995). Bethan et al. (1996) compared the height of the thermal tropopause with a one defined by the ozone gradient for four sounding stations located from $51^{\circ} \mathrm{N}$ to $79^{\circ} \mathrm{N}$. They found that the ozone tropopause lay below the thermal tropopause with an average difference of $780 \mathrm{~m}$. Recent studies indicate that the dynamical definition of the tropopause is better appropriate than the thermal one to deal with the UTLS ozone distribution (Zahn et al., 1999; Wirth, 2000). For all these reasons, we have chosen to consider a mixing zone $30 \mathrm{hPa}$ (approximately $750 \mathrm{~m}$ at this altitude) thick around the local tropopause (dynamically defined as the surface $\mathrm{PV}=2 \mathrm{pvu}$ ). This definition of the tropopause is in perfect agreement with the analysis made by Brunner et al. (2001). They found that "a value of 2 pvu appears to be at the lower limit of a tropopause region while air at 3 pvu already reveals a distinct stratospheric character."

To investigate the vertical variations in the UT and in the LS we have decided on selecting pressure intervals $(30 \mathrm{hPa}$ thick basically) characteristic of the two different regions leading to a new set of ozone climatologies. One important issue for this new set of climatologies is to be sure that we are not going to dismiss any data from any of the 5 MOZAIC flight levels (196, 216, 238, 262, and $287 \mathrm{hPa}$ ). Figure 1 gives the distribution of the five pressure intervals (i.e. $30 \mathrm{hPa}$ thick layers) for the new set of climatologies compared to the five constant pressure flight levels. This is an example based on the data recorded at the vicinity of New York City for the year 1997. We see that our definition for the five pressure intervals encompasses all aircraft data at cruising levels. However, one can notice that the highest pressure interval is about 


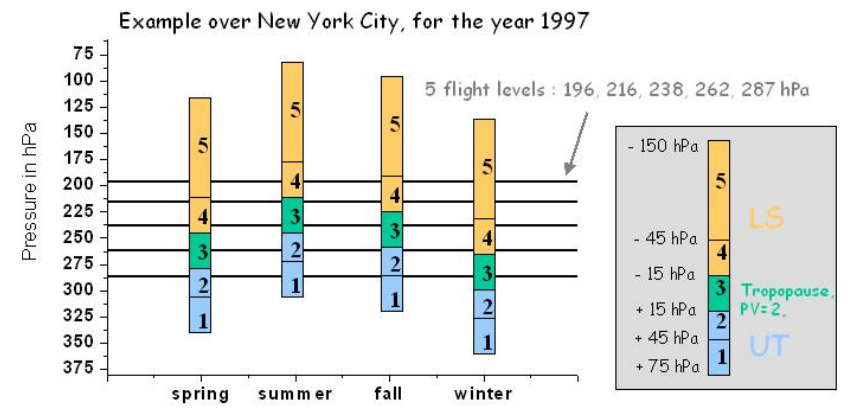

Fig. 1. Altitude range of the five pressure intervals defined for this new set of climatology compared to the altitude of the five constant pressure flight levels $(196,216,238,262$, and $287 \mathrm{hPa})$. This example has been drawn from data recorded in 1997 at the vicinity of New York City.

$105 \mathrm{hPa}$ thick in order to get all the measurements recorded on the flight level $196 \mathrm{hPa}$ when the tropopause is very low in winter for example. An equivalent problem could happen in the summer for the lowest flight level $287 \mathrm{hPa}$ but this one is the least documented, less than $5 \%$ of the data (Thouret et al., 1998a). Occurrences of tropopause pressure lower than $212 \mathrm{hPa}(=287-75 \mathrm{hPa})$ do not happen regularly and do not greatly impact our statistics. On the other hand we do not want to incorporate in this new set of UTLS climatology any data that are characteristic of the mid troposphere as it could be the case at the vicinity of the documented airports if we stretch the thickness of the lowest pressure interval. Thus we will present and analyze in Sect. 5 the ozone distribution for five levels characteristic of both, the UT (pressure intervals 1 and 2) and the LS (pressure intervals 4 and 5) regardless of the seasonal variation of the tropopause.

\section{The new set of ozone climatologies in the UTLS region}

In this section we will present three different kinds of results. First the horizontal mean distributions (averaged over the first 9 years of the MOZAIC programme) for the five defined pressure intervals are giving a general "picture" of the ozone in the UTLS region. Then we will assess the vertical distribution within the UTLS and finally the monthly means will be used to investigate the zonal and meridional differences. The inter-annual variability over the North Atlantic region and adjacent continents (as described previously) will be studied in the following section.

\subsection{The horizontal mean distributions}

Figure 2 gives the horizontal distribution for the pressure interval between 15 and $45 \mathrm{hPa}$ below the local tropopause (\#2 in Fig. 1). Data are averaged in cells 5 degrees latitude by 5 degrees longitude and plotted only if the area has been sampled by more than 30 points of measurements (i.e. aver- age over $15 \mathrm{~km}$ ) representing at least $450 \mathrm{~km}$. Note that there is no apparent correlation between the displayed fields and the number of observations. Besides, we point out that the selected regions are not situated on the edge of the domain and contain many cells with more than 2000 measurements. We clearly observe a summer maximum with concentrations between 70 and $90 \mathrm{ppbv}$, and a winter minimum exhibiting concentrations at about 40-50 ppbv. Mean concentrations are always lower than $60 \mathrm{ppbv}$ in winter and rarely exceed $95 \mathrm{ppbv}$ in summer. In spring, in the UT (Fig. 2), local maxima of ozone over northern Africa may be associated with STE during the southward migration of the subtropical jet as MOZAIC flight levels are favorable to cross tropopause folds hanging below the subtropical jet. It is interesting to notice that tropospheric distributions appear relatively homogeneous over this NAFC region. The distribution for the pressure interval between 45 and $150 \mathrm{hPa}$ above the local tropopause (\#5 in Fig. 1) presented in Fig. 3 is very different. Here we clearly see a spring maximum with most of the gridded average concentrations between 300 and $500 \mathrm{ppbv}$, and a fall minimum showing concentrations at about 150250 ppbv. Throughout the year, the highest concentrations appear over Canada and Greenland. Indeed, it is interesting to notice a meridional gradient in this LS distribution about $1-2 \mathrm{~km}$ above the local tropopause. The distributions of ozone relative to the thermal tropopause presented by Logan (1999) do not exhibit such a gradient, but a recent analysis from Pan et al. (2004) does show a difference above the thermal tropopause between the ozone concentrations near $40^{\circ} \mathrm{N}$ and near $65^{\circ} \mathrm{N}$. About $2 \mathrm{~km}$ above the tropopause most of the concentrations near $40^{\circ} \mathrm{N}$ are lower than $200 \mathrm{ppbv}$ while they are much greater near $65^{\circ} \mathrm{N}$ (Fig. 5 in Pan et al., 2004 ) in perfect agreement with our dataset. Finally, such a meridional gradient in Fig. 3 may actually characterize both the "tropically controlled transition region" as defined by Rosenlof et al. (1997) with lower values south of $40^{\circ} \mathrm{N}$ and the stratospheric part of the "middle world" or "lowermost stratosphere" (under the influence of the Brewer-Dobson circulation) with stronger concentrations north of $50^{\circ} \mathrm{N}$. According to Hoor et al. (2005), the influence of tropical tropospheric air upon the first region maximizes in summer and autumn. Indeed, our Fig. 3 exhibits the strongest gradient in summer.

\subsection{The vertical distribution in the UTLS}

Figure 4 presents the seasonal vertical profiles within the UTLS scaled to the tropopause altitude for the three selected regions as introduced before, Europe, Eastern US and Iceland (see Table 1 for coordinates). Globally, it shows that the vertical gradient between pressure interval 1 ( $60 \mathrm{hPa}$ below the tropopause) and pressure interval 2 ( $30 \mathrm{hPa}$ below the tropopause) is very weak with less than $10 \mathrm{ppbv} / 30 \mathrm{hPa}$. For these two levels, ozone concentrations maximize in July. On the contrary, vertical gradients between 


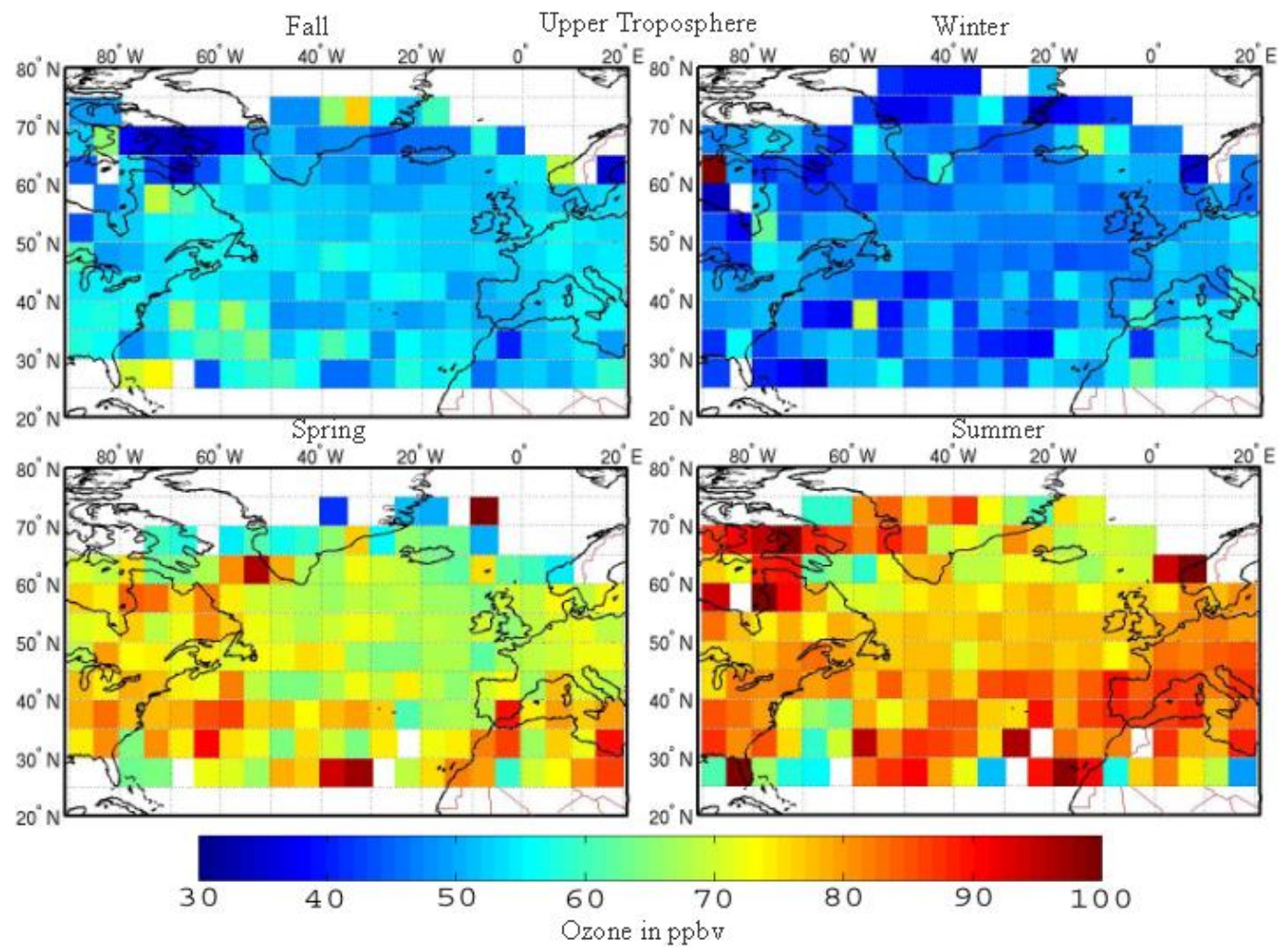

Fig. 2. Ozone seasonal and horizontal distribution for the pressure interval between 15 and $45 \mathrm{hPa}$ below the local tropopause. Averages have been made seasonally from data collected between August 1994 and December 2003 over areas five degrees latitude by five degrees longitude.

pressure intervals $4(30 \mathrm{hPa}$ above the tropopause) and 5 (60 $\mathrm{hPa}$ above the tropopause) are much greater with about $100 \mathrm{ppbv} / 30 \mathrm{hPa}$ characterizing the steep increase of ozone in the lower stratosphere compared to the upper troposphere. Above the tropopause, concentrations clearly show a maximum in April. For the following of our study, because there is no strong vertical gradient in the UT and no large phase difference in the LS, in order to increase the amount of data and thus the significance of the findings, we have decided to merge pressure intervals $1 \& 2$ to get only one level characteristic of the UT and to keep only the pressure interval 5 to characterise the LS. From now on, the term UT stands for altitudes between 15 and $75 \mathrm{hPa}$ below the surface 2 pvu, and the term LS stands for altitudes greater than $45 \mathrm{hPa}$ above the tropopause. The tropopause region remains the pressure interval 3 as described before. Figure 5 presents the seasonal cycles in the UTLS for the three selected regions over the NAFC. As already noticed in the discussion of the horizontal distributions (Figs. 2 and 3), the seasonal cycles exhibit a clear summer maximum in the UT and a clear spring maximum in the LS. Eastern US and Europe correspond to same latitude range while Iceland is situated further north (see Table 1 for coordinates). So, it is not surprising to find higher stratospheric concentrations over this latter region. In the
UT, concentrations over Iceland are very similar to the ones over Europe, while the Eastern US present slightly greater values. The seasonal variations of ozone concentrations for the tropopause region clearly show that this mixing zone defined as a layer $30 \mathrm{hPa}$ thick around the surface $\mathrm{PV}=2 \mathrm{pvu}$ is a transition zone between the typical upper troposphere and lower stratosphere with no significant regional difference. The cycle exhibits the stratospheric properties with a maximum in spring and a fall minimum but the concentrations are not "high enough" to be really characteristic of the lower stratosphere. They barely exceed $120 \mathrm{ppbv}$ in late spring and are always greater than 60-70 ppbv in fall and winter. Note that if we had used a tropopause centered on the surface $P V=3$ pvu the seasonal cycle for this pressure interval \#3 would have been a typical lower stratospheric cycle (higher concentrations throughout the year). It is interesting to note the differences with the results obtained by Logan (1999) using the ozonesondes data recorded at Hohenpeissenberg and Wallops Island. These two stations are characteristic of the mid northern latitudes. The medians at the tropopause she describes, exhibit a maximum in June at about $150 \mathrm{ppb}$ and a minimum in winter. Our data presented here show a late spring maximum (May) with lower mean concentrations. The difference certainly comes from the difference in the 


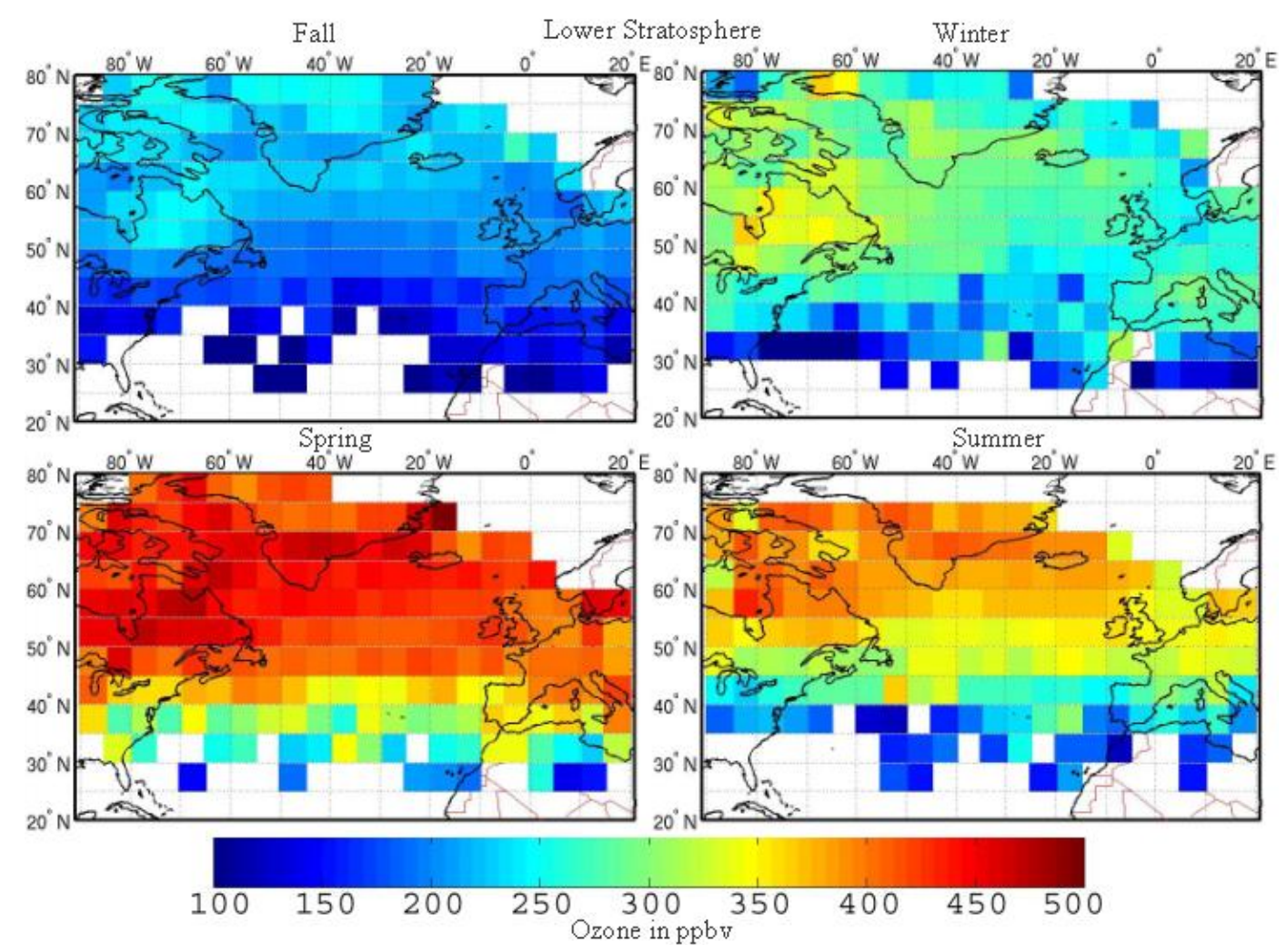

Fig. 3. Ozone seasonal and horizontal distribution for the pressure interval between 45 and $150 \mathrm{hPa}$ above the local tropopause. Averages have been made seasonally from data collected between August 1994 and December 2003 over areas five degrees latitude by five degrees longitude.

definition of the tropopause. Logan (1999) used the thermal tropopause. Given that it is above the "ozone tropopause", according to Bethan et al. (1996), it is understandable to find higher concentrations with this definition compared to ours that seems to be more appropriate. Besides, notice that Wallops Island is situated in a baroclinic zone characterized by large ozone gradients. Cooper et al. (2005) recently discussed some problems with the Wallops Island ozonesonde and showed systematic differences with the MOZAIC profiles recorded over New-York or Boston. Ozonesondes data are always higher than the MOZAIC ones. This could be related to a combination of instrumental problems and a sampling bias in the Wallops data.

Thus, the first result of this analysis lies in Fig. 5 because it clearly exhibits the phase change between the UT and the LS when we discriminate the two reservoirs using the surface 2 pvu to define a $30 \mathrm{hPa}$ thick tropopause. On a climatological point of view, we can conclude that over the NAFC ozone concentrations in the UT do not exhibit clear regional differences and maximize in June (about 70-80 ppbv) and minimize in December (40-50 ppbv). In the LS, meridional gradients play a more important role but concentrations maximize everywhere in April (400-450 ppb).
Finally, it is interesting to note that concentrations at the tropopause may be approximate by a sine seasonal variation with a maximum in May (120 ppbv) and a minimum in November ( $65 \mathrm{ppbv})$. Then, the synthetic definition for a monthly mean climatological ozone value at the tropopause could be the following: $91+28 \sin \left(\mathbf{P i}^{*}(\mathbf{M o n t h}-2) / \mathbf{6}\right)$. Such a definition has been inspired by the study from Zahn et al. (2004). Figure 6 shows the comparisons between the recorded data and these theoretic monthly mean values for the three regions. The sine approximation is quite good for Iceland and satisfactory for US. However, this is not ideal for April and October to December over the US and over Europe for late winter and spring where the differences reach 8 to $12 \mathrm{ppbv}$. This mathematical fit has a particular interest as it gives an indication of the seasonal variations of the ozone monthly mean concentrations at the tropopause. It may help in models validation or in dataset analyses. Such information may help to discriminate stratosphere to troposphere air masses based on a variable ozone threshold. For example, it is an improvement from Thouret et al. (1998) where a single rude 100 ppbv threshold was used. 

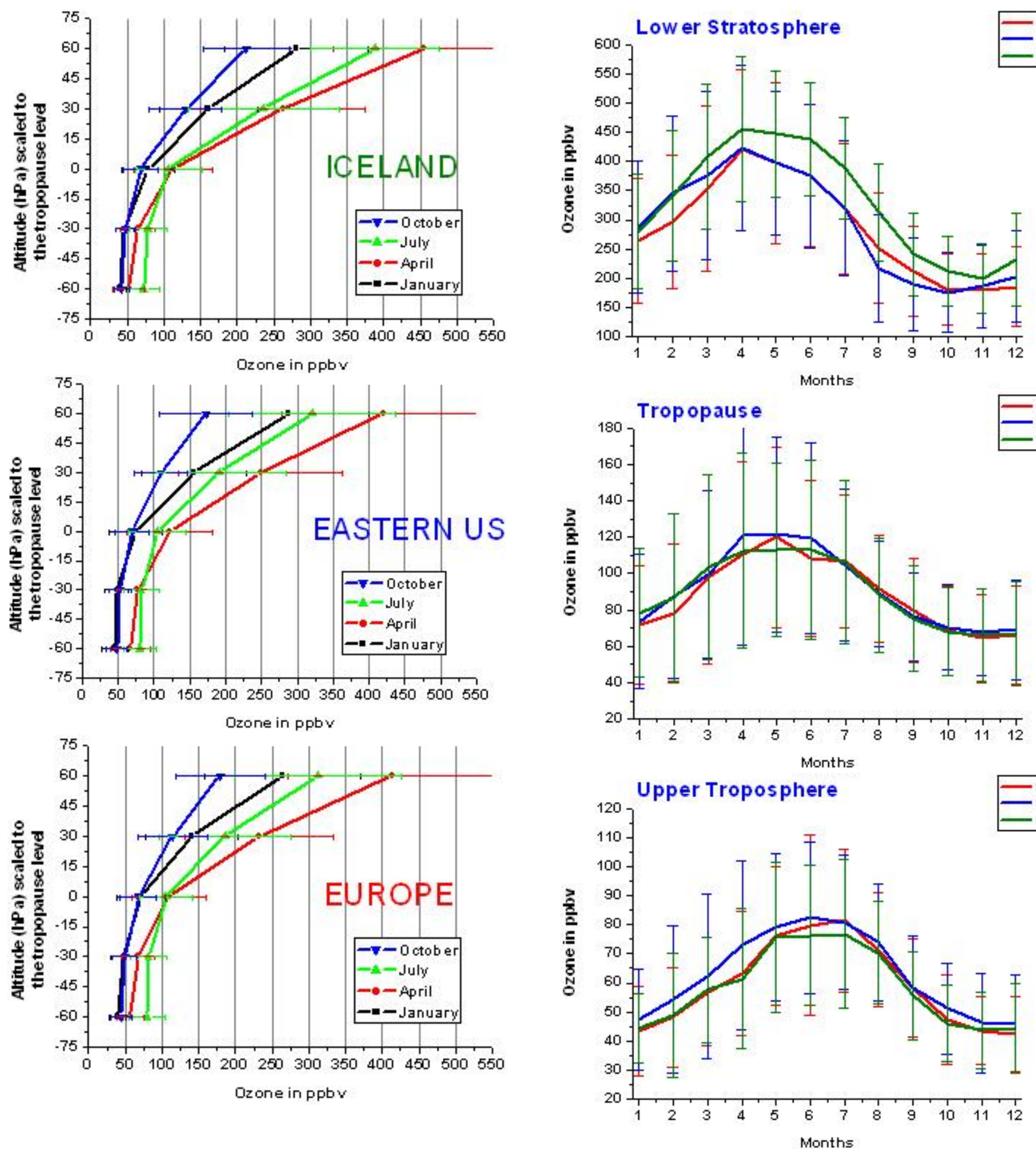

Fig. 4. Ozone monthly mean vertical profiles (in ppbv) scaled to the tropopause altitude over the three selected regions Europe, Eastern US, Iceland. Coordinates are given in Table 1. Only one month has been chosen to be characteristic of each season. January for winter, April for spring, July for summer and October for fall. Averages have been made over the entire sampling period: August 1994-December 2003. Horizontal bars give the standard deviations from the mean.

Fig. 5. Ozone seasonal cycles and associated standard deviations for the three defined levels of interest UT, tropopause and LS over the three selected regions Europe, Eastern US, Iceland. Coordinates are given in Table 1. Averages have been made over the entire sampling period: August 1994-December 2003. 


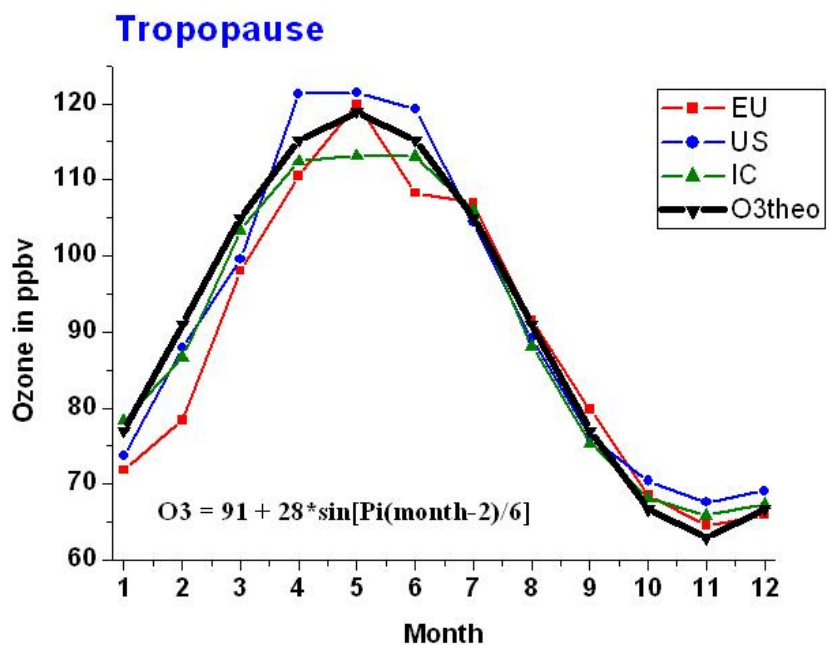

Fig. 6. Comparison over the three selected regions of the ozone seasonal cycles recorded at the tropopause and a theoretical sine variation defined for every month as $\mathrm{O} 3($ month $)=91+28 * \sin \left[\mathrm{Pi}^{*}\right.$ (month2)/6].

\section{The inter-annual variability}

In the previous section we have presented the data tropopause-scaled averaged over a 9.4 years period. The length and the density of the MOZAIC dataset now allow a first assessment of the inter-annual variability in the UTLS, at least over selected regions as said previously. The analysis of inter-annual variability throughout the troposphere over the main sampled airports is the subject of a companion paper (Zbinden et al., 2006).

Figure 7 presents the annual means from 1995 to 2003 over the three defined levels for the three selected regions: Iceland, Eastern US, and Europe and the average over the sampling period is given in Table 1. As said previously, it is interesting to note that in the UT, Eastern US present greater concentrations (between 2 and 5 ppbv throughout the sampling period) than Europe and Iceland. In the LS, concentrations over Iceland are well above the other ones (at least 20 ppbv higher). This figure exhibits the $15 \%$ amplitude between the minima and the maxima in the UT (i.e. $10 \mathrm{ppbv}$ difference), at the tropopause (about $10 \mathrm{ppbv}$ as well) and in the LS (about $50 \mathrm{ppbv}$ difference) for the three regions. It also clearly appears that the years 1998 and 1999 seem to be anomalous throughout the UTLS.

To give further details Figs. 8 and 9 present the monthly mean ozone time series from August 1994 to December 2003 over the three regions for the UT and the LS respectively, along with the fitted line giving the linear trend. This latter is summarized in Table 1 along with the overall mean. The results are a little bit surprising. The increase in the UT (about $1.0 \% / y r)$ is too high compared to what is said in the literature (i.e. Logan et al., 1999). The only agreement with Logan et al. (1999) is found over Europe in the UT. Still according
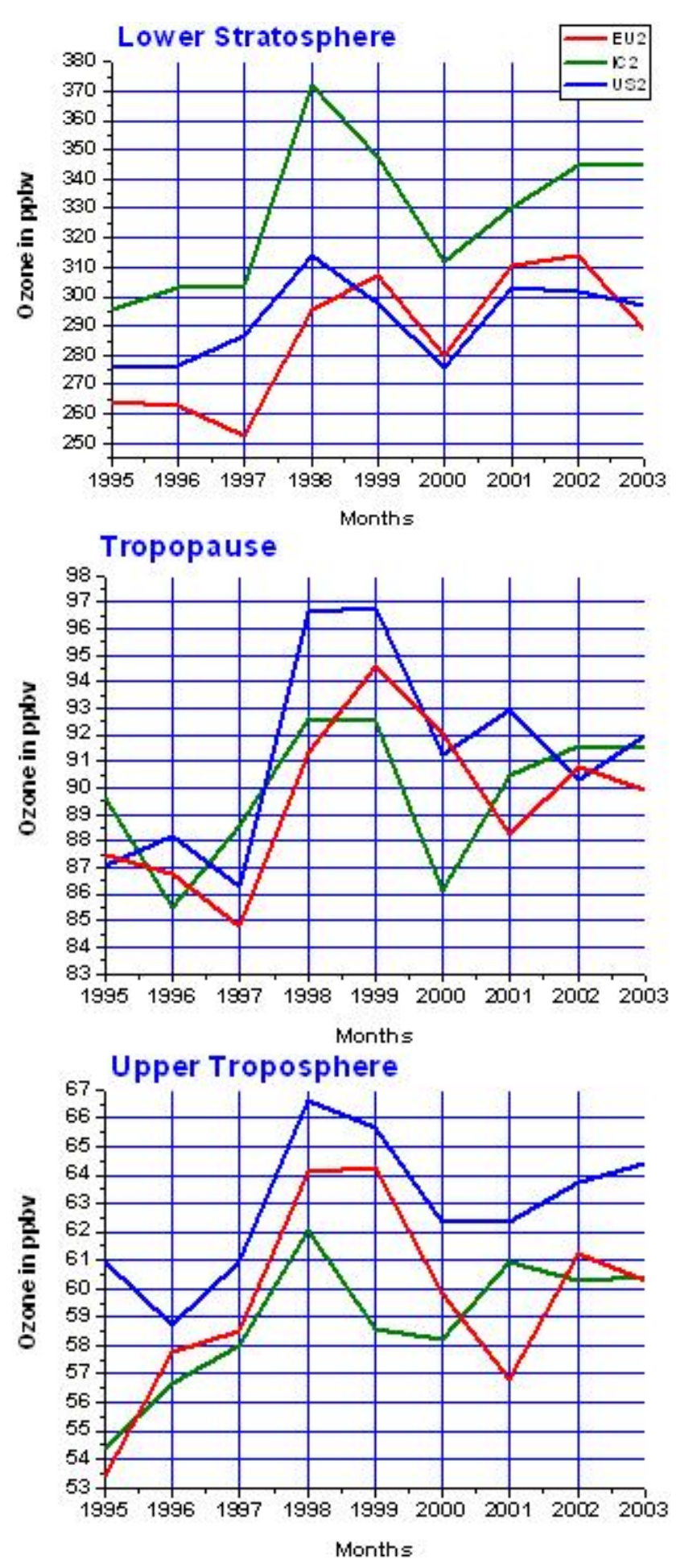

Fig. 7. Time series of the annual means for the three levels of interest UT, tropopause and LS over the three selected regions Europe, Eastern US and Iceland. Averages have been made from 1995 to 2003. 

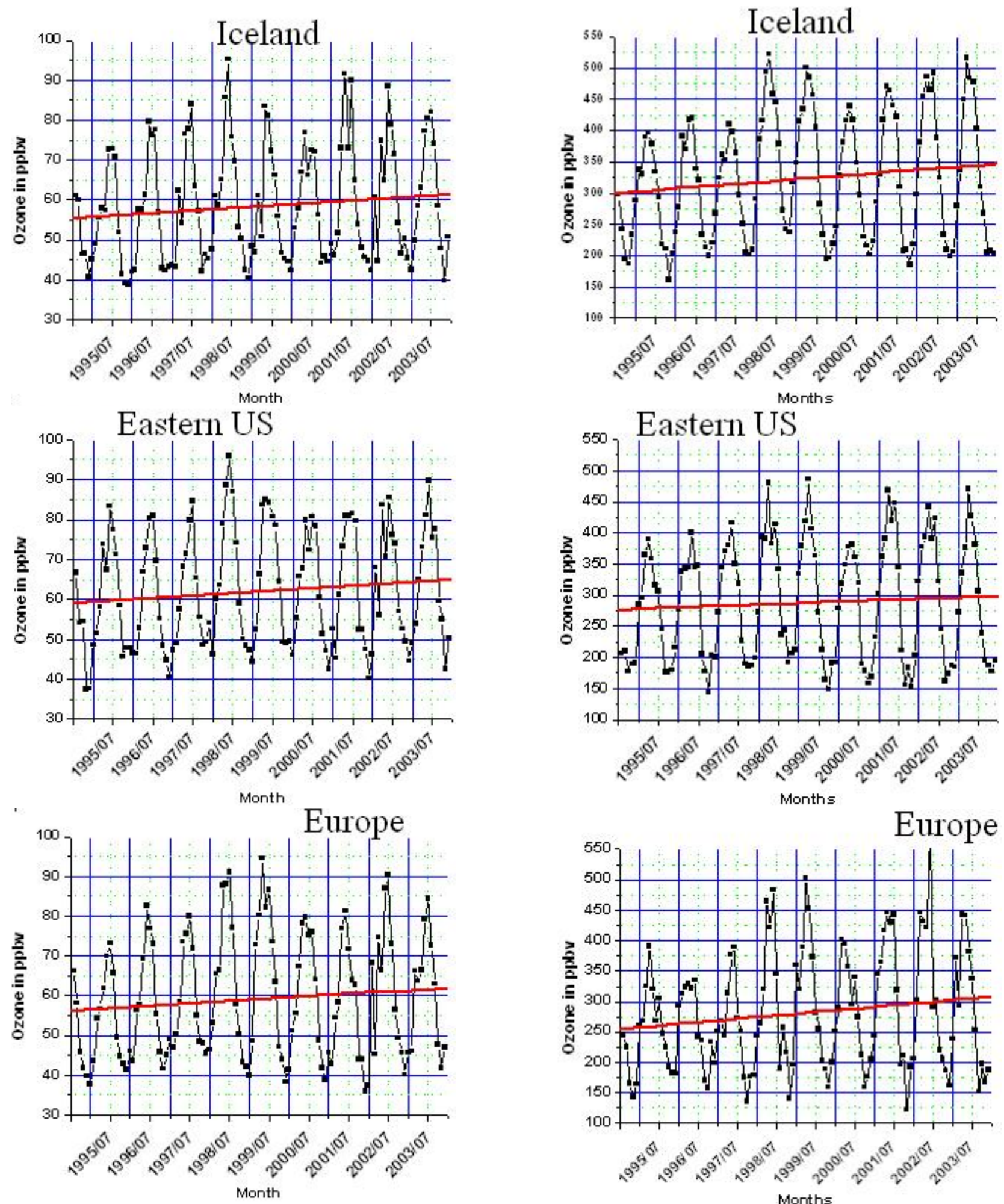

Fig. 8. Time series of ozone monthly means in the UT over the three selected regions Europe, Eastern US and Iceland, along with the fitted line (in red) characterizing the increase rate. Averages have been made from data collected between August 1994 and December 2003.

Fig. 9. Time series of ozone monthly means in the LS over the three selected regions Europe, Eastern US and Iceland, along with the fitted line (in red) characterizing the increase rate. Averages have been made from data collected between August 1994 and December 2003. 

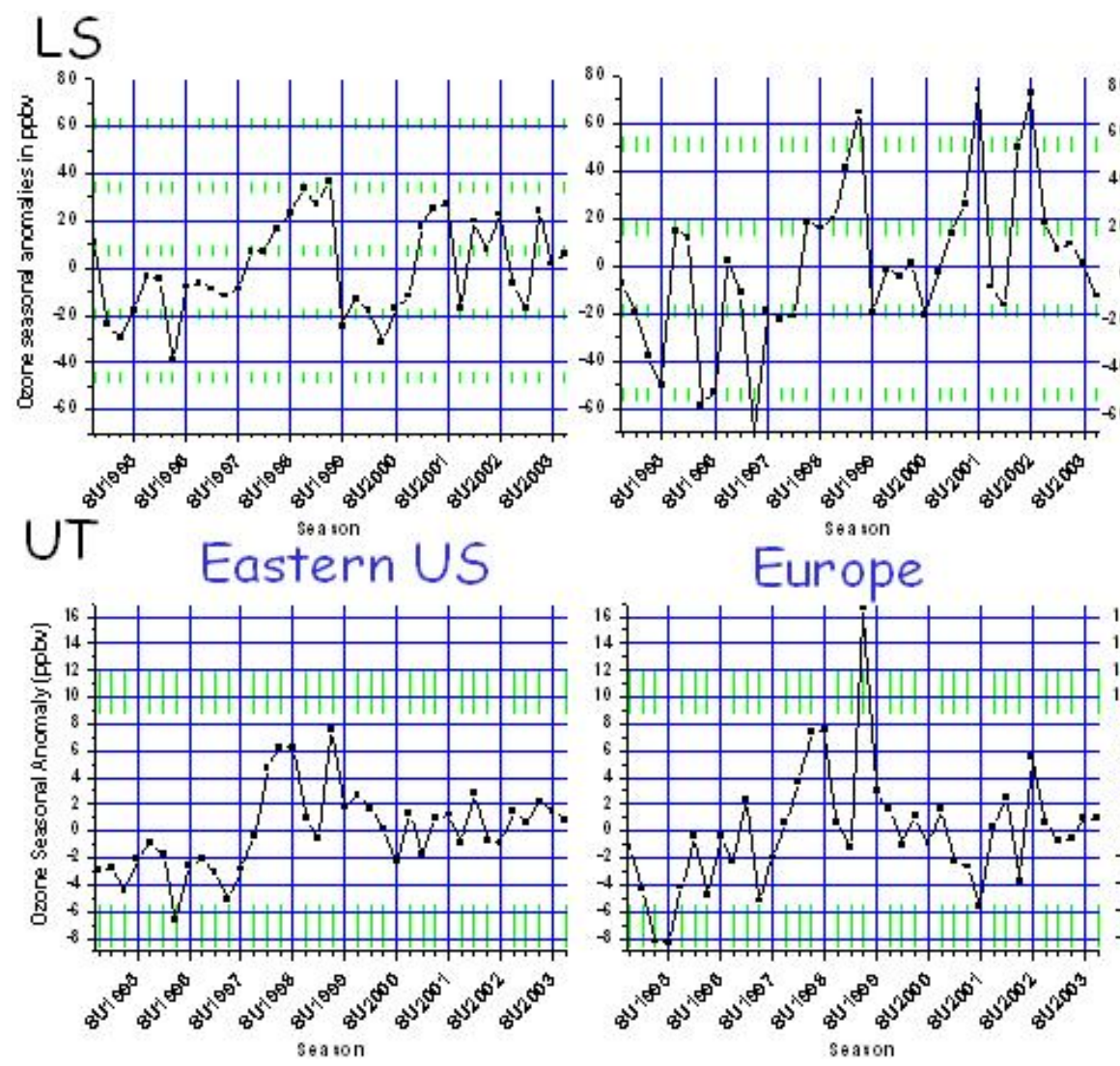

Europe

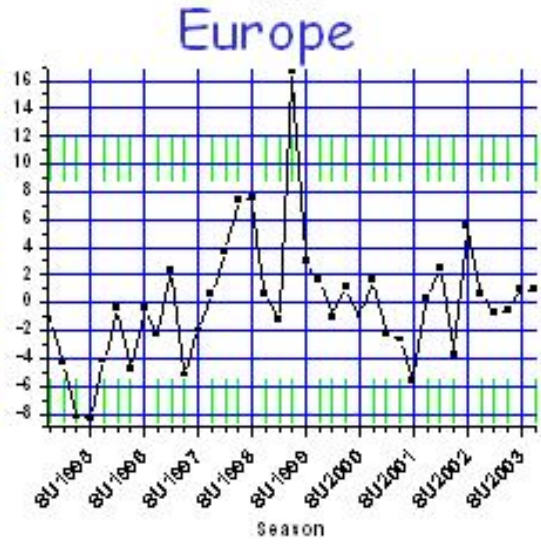

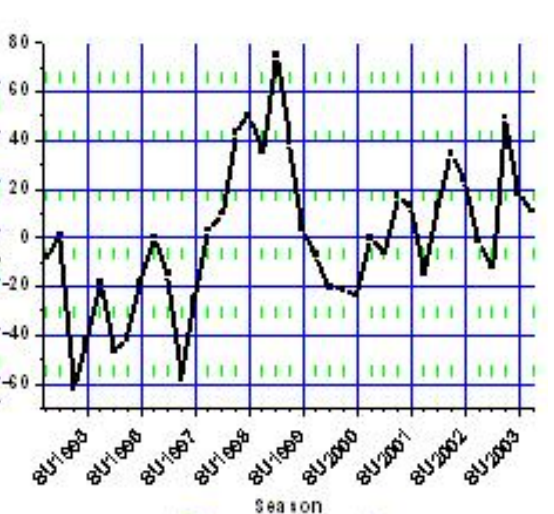

Iceland

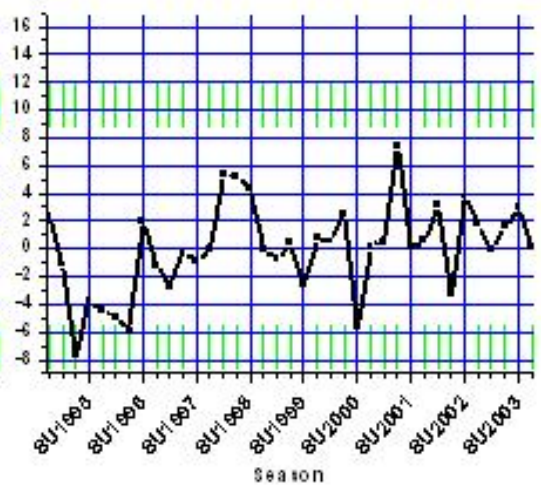

Fig. 10. Ozone seasonal anomalies in the UT and the LS over the three selected regions Europe, Eastern US and Iceland. Such anomalies have been calculated as the difference between the seasonal average and the climatological seasonal mean (same weight for every month) from data collected between August 1994 and December 2003.

to the previous literature, we expected a decrease in the LS and we get a similar increase of 0.8 to $1.99 \% / y r$. However, Tarasick et al. (2005) have recently analyzed the vertical distribution of ozone over Canada and have shown that when the data for 1991-2001 only are considered, the trends are positive, even in the lower stratosphere (between 0.8 and $2 \% / y r$ depending on the station).

6.1 The Seasonal anomalies to highlight the "1998-1999 anomaly"

Actually, as seen in previous figures (Figs. 7, 8 and 9), the time series (monthly or annual means) reveal particular high values recorded in 1998 and 1999. Thus Fig. 10 gives the seasonal anomalies calculated as the seasonal mean minus the seasonal climatological mean (elaborated over the 9 years) for the three selected regions and the two levels (UT and LS). A common feature is clearly highlighted: strong positive anomalies appear everywhere within the whole UTLS region between Fall 1997-Winter 1998 and Spring-Summer 1999. The maximum of deviation is observed at every level during the two spring seasons, especially noticeable in 1999. These deviations are of the same order of magnitude in the
UT and in the LS, i.e. 10 to $15 \%$ in both layers. That corresponds to a 6-10 ppbv enhancement in the UT compared to an average of about $60 \mathrm{ppbv}$ and an enhancement of 35$75 \mathrm{ppbv}$ in the LS compared to an average of $300 \mathrm{ppbv}$ (Fig. 7 and Table 1). It means that higher concentrations have been recorded throughout the year in 1998 up to spring-summer 1999. As a consequence, we get a different tropospheric seasonal cycle in 1999. Figure 11 shows the seasonal cycles in the UT for Europe and Eastern US. Over Europe the maximum appears in May in 1999 while it is in June-July for the other years. For Eastern US, the seasonal cycle in 1999 presents a broad spring-summer maximum. This change of phase in the UT seasonal cycle is not related to an artifact of the method or an anomaly in the tropopause height in 1998 globally or in May 1999 in particular. Figure 12 shows the box charts (summary of the frequency distribution) for ozone (top) and tropopause height (bottom) over Europe and Eastern US recorded every month of May from 1995 to 2003. The concentrations recorded in May 1998 and May 1999 have been particularly high compared to the June and July records of the same years but it is not due to our sampling method (through PV analyses) because there is no similar anomaly 

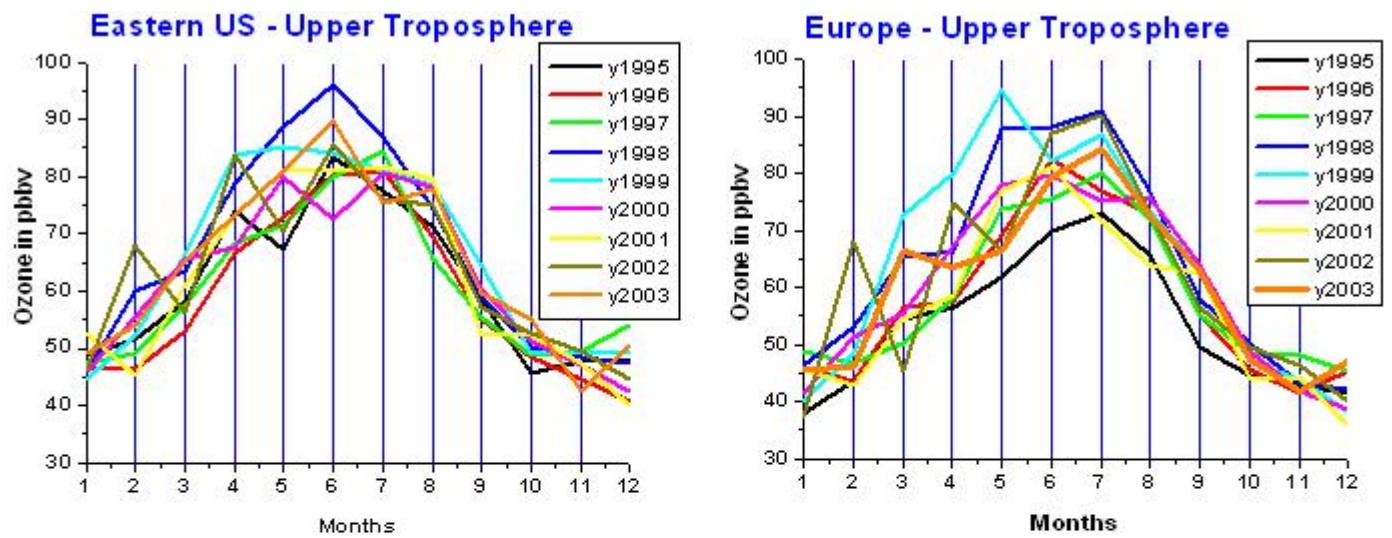

Fig. 11. Comparison of the 9 seasonal cycles of ozone recorded in the UT over Europe and the Eastern US from data recorded from 1995 to 2003.
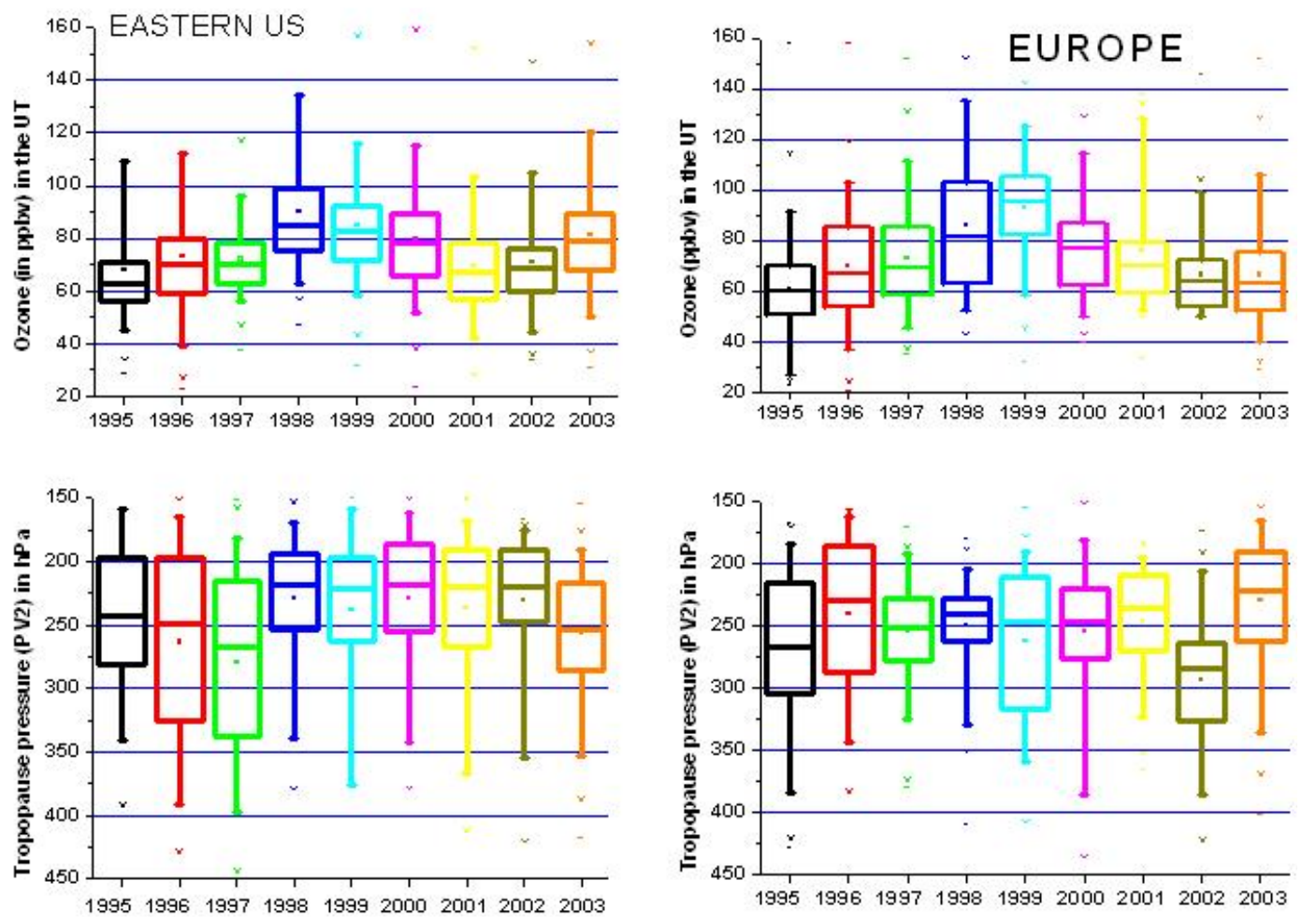

Fig. 12. Statistical analyses as "box charts" for the 9 months of May for ozone distributions (top panels) and tropopause altitude ranges (bottom panels). The horizontal bars in the box give the median, while the box themselves extend from the $25 \%$ and the $75 \%$ percentiles. The small squares inside the box give the mean and the vertical bars give the standard deviations from the mean. Crosses give the $1 \%$ and $99 \%$ percentiles.

in the tropopause height. The years 1998 and 1999 (although at a lesser extent) really appear as anomalous. Because the seasonal anomalies are of the same order of magnitude in the UT and in the LS, we can further argue that the reservoirs are probably not independent. Because the short-term variability of total ozone columns is mainly governed by dynamical processes in the LS, the ozone mixing ratio in the UTLS is probably driven by the same constraints. Indeed,
Seo and Bowman (2001) pointed out that tropospheric and stratospheric air masses are thought to be coexistent and relatively well mixed in the vicinity of the tropopause. This notion of "vicinity of the tropopause" could be 2 to $3 \mathrm{~km}$ thick in our study. On the other hand, we admit that the whole UTLS region is more driven by the lower stratosphere dynamic than the troposphere itself (Perlwitz and Graf, 1995). Because the MOZAIC programme also provides vertical 
EUROPE - Lower Stratosphere

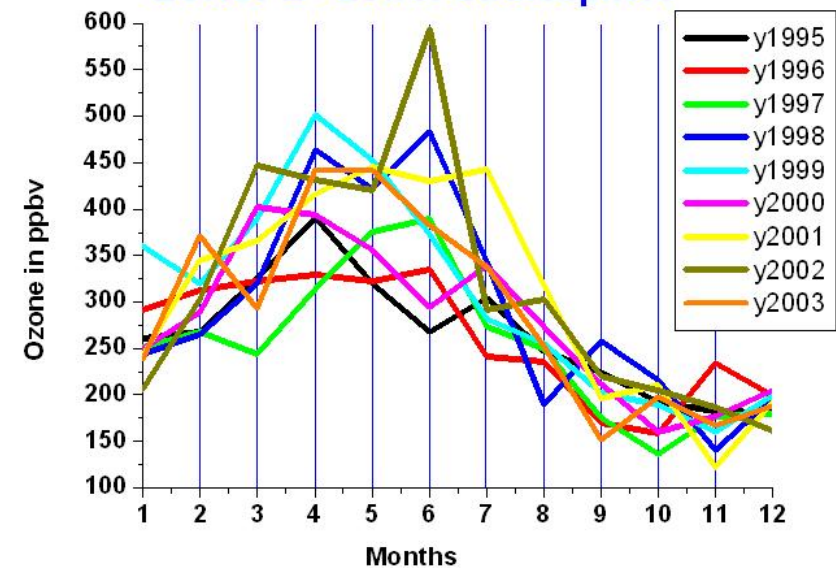

Fig. 13. Comparison of the 9 seasonal cycles of ozone recorded in the LS over Europe from data recorded from 1995 to 2003.

profiles over documented airports, we know that such an anomaly in 1998-1999 has been observed further down in the troposphere (Zbinden et al., 2006). Unfortunately, altitudes of the MOZAIC data never exceed $12 \mathrm{~km}(196 \mathrm{hPa})$. Rao et al. (2003) presented a climatology of UTLS ozone over northern Europe and after their Fig. 3 the anomaly in 1998-1999 is present within an altitude range from 500 to $100 \mathrm{hPa}$ at least. According to J. A. Logan (personal communication) such anomalies have been observed in the sounding data from Hohenpeissenberg (Germany) and Wallops Island (North-eastern US) and they appear to be mostly present between 400 and $60 \mathrm{hPa}$ with a maximum of intensity between 250 and $100 \mathrm{hPa}$ (almost the same altitude range as in our study, i.e. $287-196 \mathrm{hPa}$ corresponding to the five flight levels).

Another strong positive anomaly appears in the LS in summers 2001 and 2002 for the three regions, which is especially noticeable over Europe. The magnitude of the anomalies there is even greater than in 1999. As in 1998-1999 the consequence is a different seasonal cycle for these two years with a maximum in June or July instead of a maximum in April as is the case for the previous years. Indeed Fig. 13 shows the 9 seasonal cycles over Europe in the LS. In that layer, high concentrations are of course not related to the definition of the tropopause. The LS anomalies in summers 2001 and 2002 are not accompanied with similar anomalies in the UT on contrary of what happen in 1998-1999. The only exception is over Europe in summer 2002. The anomaly is there observed both in the UT and the LS.

6.2 What have been different in 1998-1999 to induce such a feature?

Extremes of many variables in the years 1998 and 1999 have been documented in the literature such as $\mathrm{CO}, \mathrm{CH}_{4}$, global temperature, stratospheric and total ozone, stratospheric intrusions, North Atlantic Oscillation (NAO), etc.

Enhanced $\mathrm{CO}$ columns (along with $\mathrm{C}_{2} \mathrm{H}_{6}$ and $\mathrm{HCN}$ ) have been recorded in Switzerland in 1998 (Rinsland et al., 2000). The authors related that to the period of widespread wildfires during the strong El Nino warm phase of 1997-1998. This last El Nino warm phase event is not the only cause of high CO concentrations in 1998. Wotawa et al. (2001) reported summertime CO concentrations much higher in 1998 than the previous years and the following ones (17\% higher in 1998 than the three previous years). They attributed this CO anomaly to the particular extensive boreal fires in North America and Russia this particular year. Spichtinger et al. (2004) also reported $\mathrm{CO}$ anomalies north of $35^{\circ} \mathrm{N}$ from November 1997 to June 1999 with a first peak in May 1998 likely to be caused by northward transport of emissions from the subtropics (southeast Asia). Anomaly in methane $\left(\mathrm{CH}_{4}\right)$ has also been observed in 1998. Dlugockenky et al. (2001) calculated that the growth rate increases from $3.9 \mathrm{ppb} / \mathrm{yr}$ in 1995-1997 to $12.7 \mathrm{ppb} / \mathrm{yr}$ in 1998 . According to the authors, this is partly due to the anomaly in temperature that is attributed to the strong El-Nino event in 1997. It is well recognized that the year 1998 has been the warmest year of the last century. However, the direct and indirect influence on the ozone production and/or changes in meteorology is still unclear. Because they are the major ozone precursors in the troposphere, $\mathrm{CO}$ and $\mathrm{CH}_{4}$ anomalies may partly contribute to the maximum of ozone observed in the UT. That may contribute to an increase of the tropospheric ozone background at global scale in the troposphere. Indeed, according to Galanter et al. (2000), the boreal forest fires of Siberia and the Northwest territories contribute 10 to $20 \%$ of the ozone produced in the lower troposphere over those regions in summer. Indeed, anomalies in the UT have been recorded from the beginning of 1998 to mid-1999 in phase with the CO anomalies reported by Spichtinger et al. (2004). However, the explanation of the ozone anomalies in the UTLS may also lie in stratospheric causes as we observe similar deviation from the mean up to $60 \mathrm{hPa}$. Thus, intense biomass burning in the Asian tropics in 1997 and extra tropical stratospheretroposphere exchanges in 1998-1999 seem to have a common cause and a global impact through the strong El Nino event in 1997. Shapiro et al. (2001) had previously shown that ENSO has an important impact on dynamical features in the extra-tropics. A recent analysis from Zeng and Pyle (2005) shows that there is a close relationship between ENSO and STE at global scale leading to stronger ozone concentrations both in the troposphere and the LS.

In general, we know that stratospheric ozone has decreased by about 5\% between 1979 and 1994-1997 in winter/spring seasons, but in 1998 a northern stratospheric ozone increase was observed. Indeed total ozone in March 1998 almost reached the levels of the 1980s (World Meteorological Organization, 1999). The total ozone columns calculated from the TOMS data as zonal means for the latitude range 
$35-50^{\circ} \mathrm{N}$ present a slight maximum in 1998 ( $+3 \%$ compared to the period 1997-2002, i.e. available data in public access from the web site). As said previously, Tarasick et al. (2005) have shown positive trends in the lower stratosphere between 1991 and 2001 while the longer period 1980-2001 exhibits negative linear trends. They pointed out that ozone in the LS has rebounded at all levels below about $63 \mathrm{hPa}$ compared to previous trends calculated before 1993. At last, they suggest that this rebound may be partly a result of small changes in the atmospheric circulation, rather than a recovery of the ozone layer from halocarbon-induced depletion.

The ozone distribution in the LS is driven more by dynamics than chemistry so a dynamical explanation for the anomaly must be sought. Hood et al. (1999) showed that inter-annual variability of stratosphere-troposphere exchanges (STE) may play a role in the recent change of stratospheric total column ozone in the northern mid-latitudes. Morgenstern and Carver (1999) first investigated the difference between January-February 1997 and January-February 1998. They found around 30\% more filaments on the $330 \mathrm{~K}$ isentropic surface in 1997 than in 1998. Seo and Bowman (2001) presented a climatology of cross-tropopause air mass exchange on isentropic surfaces between 320 and $350 \mathrm{~K}$ (i.e. 9-12 km altitude) in the northern mid-latitudes (30$50^{\circ} \mathrm{N}$ ) LS for 8 years from 1992 to 1999 using the United Kingdom Meteorological Office assimilated data set. They partly linked the increase of the northern mid-latitude ozone column in winter/spring 1998 to a decrease in the upward transport of ozone-poor tropospheric air. The significantly decreased upward transport of ozone-poor tropospheric air appearing in 1998 spring corresponds to increased stratospheric amounts.

Many tropospheric and stratospheric features have been obviously anomalous in 1998. On contrary, no extreme behaviours have been observed in 1999. The 1998 anomaly may be a combination of various causes, some from tropospheric origin and some from stratospheric origin. However, the similarity in phase of the anomaly in both the UT and the LS and within the entire NAFC argues in favor of a coupling between the stratosphere and the troposphere. The variability of ozone in the UTLS may be linked to the variability of dynamical parameters and to anomaly circulations patterns. The North Atlantic Oscillation influence is then investigated, along with the Northern Annular Mode.

6.3 Correlation with atmospheric teleconnection indices: North Atlantic Oscillation and Northern Annular Mode

According to Baldwin and Dunkerton (2001), observations show that large variations in the strength of the stratospheric circulation, appearing above $50 \mathrm{~km}$, descend to the lowermost stratosphere and are followed by anomalous tropospheric weather regimes. In the stratosphere the Northern Annular Mode (NAM) is a large-scale anomaly circulation pattern derived from the gravity waves momentum deposi-
Table 2. Correlation factors $(\mathrm{R})$ and the associated significance value $(\mathrm{P})$ between the NAO index (as annual mean) and the ozone annual mean for the period 1995-2003 in the 3 levels of interest: UT, tropopause and LS and for the three selected regions as exhibited in Fig. 14 for UT only.

\begin{tabular}{lccc}
\hline & $\begin{array}{c}\text { Upper } \\
\text { Troposphere }\end{array}$ & tropopause & $\begin{array}{c}\text { Lower } \\
\text { Stratosphere }\end{array}$ \\
\hline Eastern US & $\mathrm{R}=0.82$ & $\mathrm{R}=0.61$ & $\mathrm{R}=0.51$ \\
$\left(3550^{\circ} \mathrm{N},-90-60^{\circ} \mathrm{W}\right)$ & $\mathrm{P}=0.006$ & $\mathrm{P}=0.08$ & $\mathrm{P}=0.16$ \\
Europe & $\mathrm{R}=0.75$ & $\mathrm{R}=0.65$ & $\mathrm{R}=0.40$ \\
$\left(3550^{\circ} \mathrm{N},-300^{\circ} \mathrm{W}\right)$ & $\mathrm{P}=0.02$ & $\mathrm{P}=0.06$ & $\mathrm{P}=0.29$ \\
Iceland & $\mathrm{R}=0.59$ & $\mathrm{R}=0.58$ & $\mathrm{R}=0.65$ \\
$\left(5570^{\circ} \mathrm{N},-60-10^{\circ} \mathrm{W}\right)$ & $\mathrm{P}=0.09$ & $\mathrm{P}=0.13$ & $\mathrm{P}=0.06$ \\
\hline
\end{tabular}

tion. It is calculated for each pressure altitude by projecting daily geopotential anomalies onto the leading empirical orthogonal function (EOF) patterns. The NAM is actually a measure of the strength of the polar vortex. We used here the monthly means at $150 \mathrm{hPa}$ (web site: http://www.nwra. com/resumes/Baldwin/nam.html). The near-surface annular mode is called the Artic Oscillation (AO), which is correlated with the North Atlantic Oscillation (NAO) over the Atlantic sector. The NAO is a large-scale oscillation in atmospheric air masses between the subtropical high and the polar low centred over the Atlantic. The NAO has a large climatic influence on the North Atlantic Ocean and surrounding landmasses. It is a major controlling factor for basic meteorological variables such as surface wind, temperature and precipitation throughout the whole of Europe and eastern North America. Meteorologists define the NAO index as the surface pressure difference between Ponta Delgada (Azores) and Stykkishomur (Iceland) (Hurrell, 1995). When the NAO is in its positive phase, low-pressure anomalies over the Icelandic region and throughout the Arctic combine with high-pressure anomalies across the subtropical Atlantic to produce stronger-than-average westerlies across the mid-latitudes. During a positive NAO, conditions are colder and drier than average over the north-western Atlantic and Mediterranean regions, whereas conditions are warmer and wetter than average in northern Europe, the eastern United States, and parts of Scandinavia.

Many studies have investigated the correlations between total ozone and the most prominent anomaly circulations patterns in the Northern Hemisphere, i.e. the NAO. With regards to the ozone distribution, most of the studies consider total ozone columns and use the NAO index as a monthly mean only for the winter (December to March). For example, Bronnimann et al. (2000) found significant correlations between total ozone at Arosa, Switzerland and indices of the North Atlantic Oscillation (NAO). Nikulin and Repinskaya (2001) analyzed winter monthly mean total ozone anomalies at northern midlatitudes in association with the large-scale 

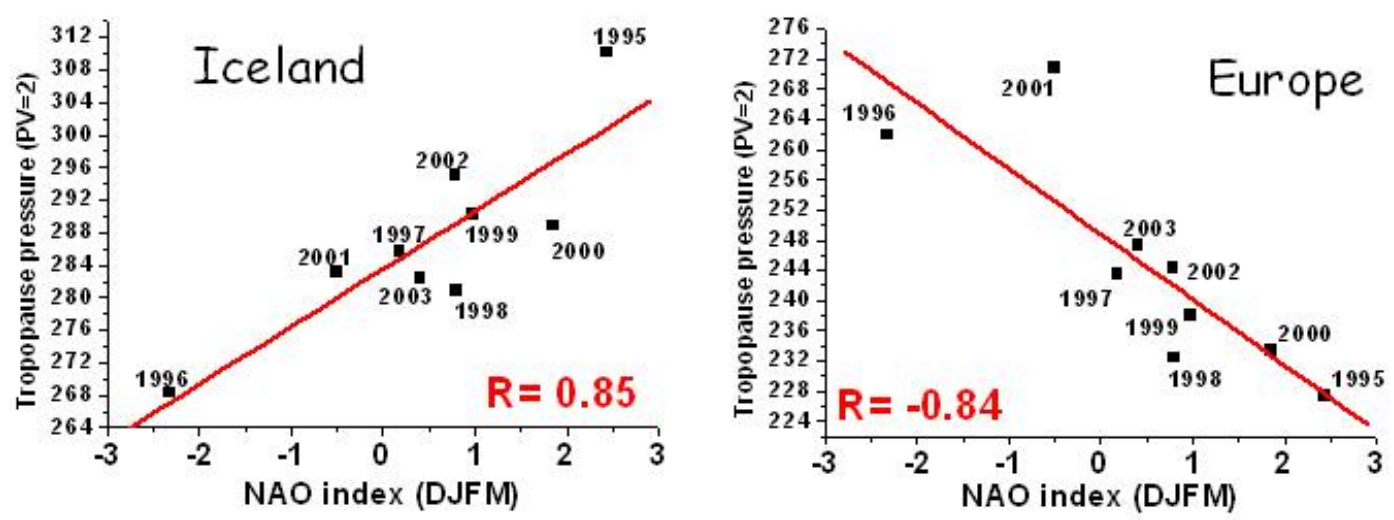

Fig. 14. Scatter plots for winter NAO indices versus tropopause altitude over Europe and Iceland as defined in Table 1 along with the fitted line and the correlation factor (in red). Winter averages have been made over the 4 months December, January, February and March, and for the 9 years of the sampling.

mode of atmospheric variability AO. They concluded their analysis by "AO and NAO decay after 1995 resulted in a total ozone increase in the mid-latitudes Northern Hemisphere. This increase was especially noticeable in 1998-1999." In our study, things are a little different as we are investigating ozone concentrations in the UTLS region and not the total column. We use the NAO index defined by Hurrell (1995, available at: http://www.cru.uea.ac.uk/ftpdata/nao.dat). We first check the agreement with Appenzeller et al. (2000) showing that NAO and tropopause pressure are strongly correlated with a distinct geographical pattern. Note that our regions of interest have also been chosen according to their results. Thus, Fig. 14 shows a strong positive correlation $(0.85)$ between the NAO index and the tropopause pressure for DJFM over Iceland and a strong negative one $(-0.84)$ over Europe. The agreement between these two studies was very important to get as it means that the MOZAIC sampling is representative of the North Atlantic region. The dynamical tropopause (at $\mathrm{PV}=2 \mathrm{pvu}$ ) at the sampling frequency of MOZAIC aircraft can be used to study the variation of the pressure dipole between the Icelandic low and the subtropical high linked to the NAO. Moreover, the MOZAIC flight tracks are not varying depending on the variations of such weather systems. Our sampling throughout the UTLS altitude range and throughout the North Atlantic is therefore statistically significant. Figure 15 shows the scatter plots of Ozone versus NAO index as annual mean for our three selected regions in the upper troposphere with an indication of the correlation factor. Because the anomalies appear from Fall 1997-Winter 1998 to Spring-Summer 1999, the annual scale seems more appropriate to investigate the relationship between the ozone mixing ratios and this index. The correlation is obvious and statistically significant; the stronger the NAO index - the higher ozone. Table 2 gives the correlation factors $(\mathrm{R})$ and the associated significance value $(\mathrm{P})$ between the NAO index (as annual mean) and the ozone an- nual mean for the period 1995-2003 in the 3 levels of interest: UT, tropopause and LS and for the three selected regions as exhibited in Fig. 15 for UT only. Note that the correlation is decreasing with altitude. The years corresponding to the most negative NAO index $(1995,1996,1997$, and 2001 ) show the lowest ozone concentrations ( 62 ppbv or less over the Eastern US, 58 ppbv or less for Iceland and Europe) while the high ozone concentration in 1998 corresponds to the maximum of the NAO index (0.25) in this time series. The year 1999 also presents quite high ozone over US and Europe (66 and $64 \mathrm{ppbv}$, respectively) with low but positive NAO index (0.04). The year 2002 is intermediate with quite high ozone associated with very low but negative NAO index. Short-term ozone variability is obviously linked to variations in the dynamical structure of the atmosphere as reflected in the tropopause pressure. This study does not aim to further investigate whether the NAO is the mechanism that explains the inter-annual variability of ozone in the "Atlantic" UTLS. Indeed, the companion analysis dealing with the entire troposphere (Zbinden et al., 2006) shows that we have recorded the same anomalies over Japan, apparently not connected to the NAO phases. The anomalies in the ozone concentrations in the UT seem then noticeable at global scale. Our study over the Atlantic sector shows that strong ozone anomalies are accompanied by positive phases of the NAO. Therefore, we only aim to suggest that the good correlation over the 9 years may lead to an empirical relationship, for example, for the 10 ppbv short term modulation of ozone annual mean in the UT.

However, the NAO does not help to explain the ozone anomalies in the stratosphere. In the LS, strong anomalies appear in the summers 2001 and 2002 (Fig. 10), which are especially noticeable over Europe (Fig. 13). Then the NAM index may help to investigate sources of such strong anomalies. It seems quite obvious to relate ozone anomalies in the LS and circulation anomalies as the ozone distribution above 

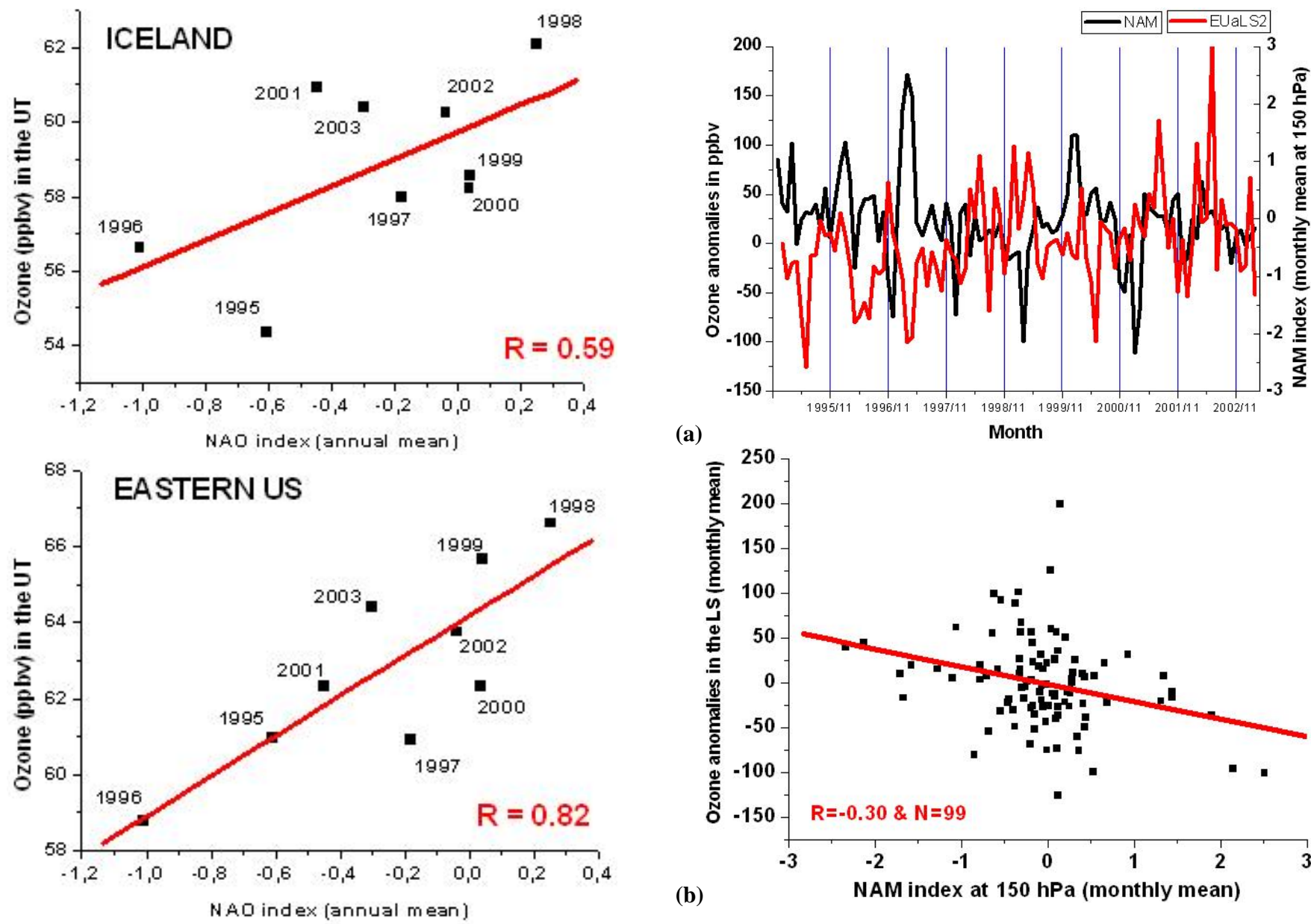

(a)
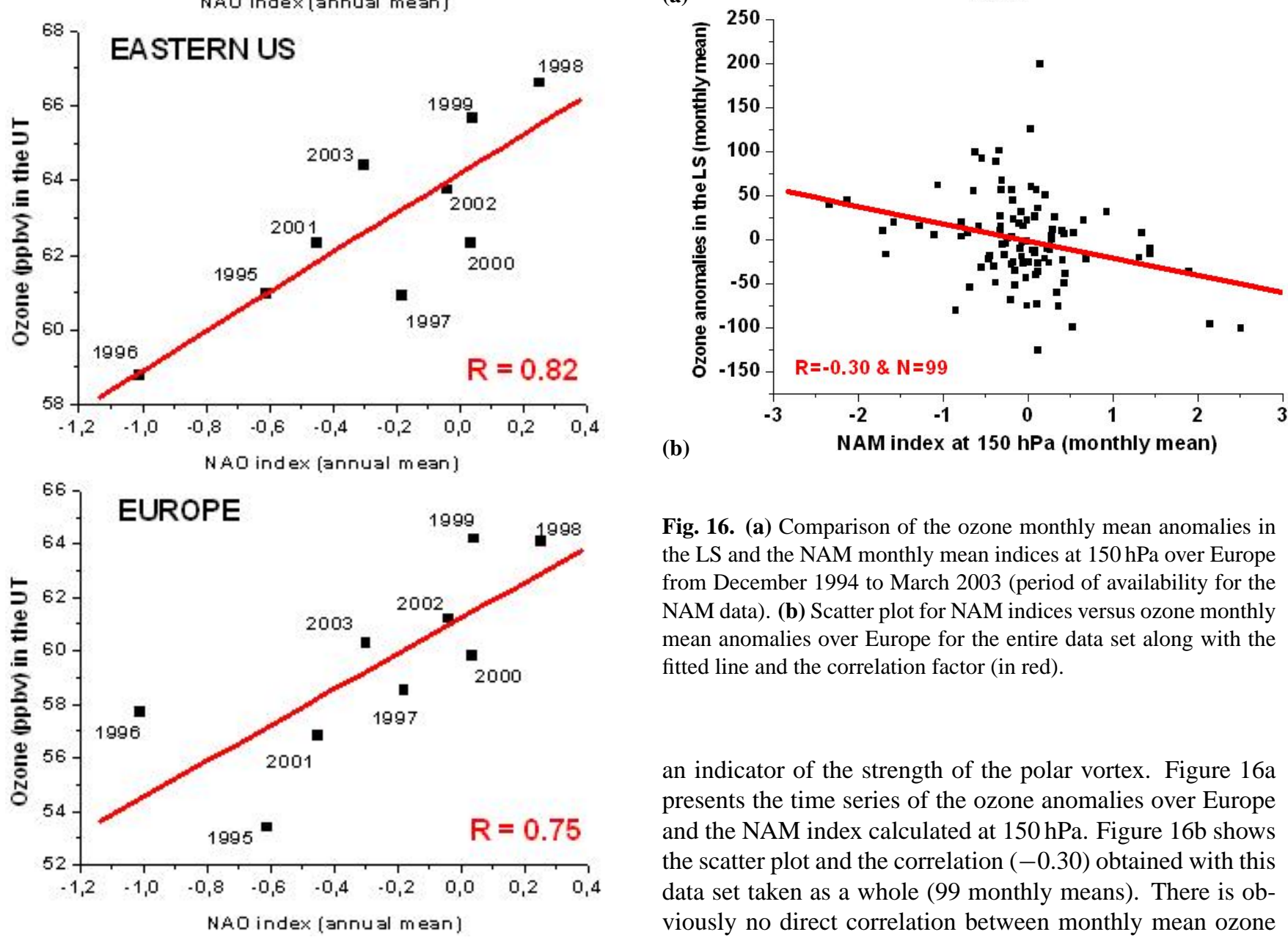

Fig. 16. (a) Comparison of the ozone monthly mean anomalies in the LS and the NAM monthly mean indices at $150 \mathrm{hPa}$ over Europe from December 1994 to March 2003 (period of availability for the NAM data). (b) Scatter plot for NAM indices versus ozone monthly mean anomalies over Europe for the entire data set along with the fitted line and the correlation factor (in red).

Fig. 15. Scatter plots for NAO indices versus ozone concentrations as annual means for the 9 years of the sampling over the three selected regions in the UT, along with the fitted line and the correlation factor (in red).

the tropopause is linked to the strength of the Brewer-Dobson circulation. As said previously, we use the NAM index as

an indicator of the strength of the polar vortex. Figure 16a presents the time series of the ozone anomalies over Europe and the NAM index calculated at $150 \mathrm{hPa}$. Figure $16 \mathrm{~b}$ shows the scatter plot and the correlation $(-0.30)$ obtained with this data set taken as a whole (99 monthly means). There is obviously no direct correlation between monthly mean ozone anomalies in the LS and the NAM indices at $150 \mathrm{hPa}$. However, it seems that a correlation may exist within the extreme events. Figure 17 is thus obtained by selecting only the extreme NAM indices (above 1 in absolute value) along with the correspondent monthly mean ozone anomaly. Thus, we get a data set containing 15 monthly means. The correlation factor is -0.78 and is statistically significant $(>99 \%)$. Then, it is obvious that anomalies in transport processes in the LS, or in strength of the polar vortex may lead to anomalies in ozone concentrations. NAM indices maximize mostly 


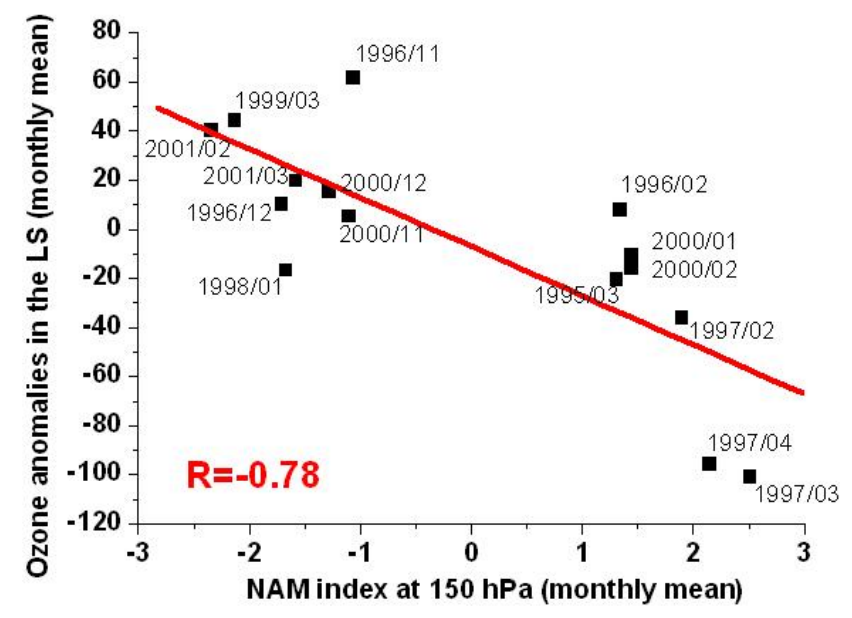

Fig. 17. Scatter plot for NAM indices versus ozone monthly mean anomalies over Europe after filtering of the lowest NAM values (less than 1 in absolute value). An indication of the 15 remaining months is given.

in spring 1997 when we have recorded the lowest ozone concentrations in the LS as annual mean (Fig. 7). On the other hand, we have recorded the strongest ozone concentrations in the LS mostly in 2001 (Fig. 13) when the NAM indices minimize in February. Our method of threshold for extracting a sub-data set leads to the same conclusion over the Eastern US and Iceland. Figure 18 presents a summary of the different correlations obtained with the various NAM thresholds applied to the data set for the three regions. For example, we see that over Europe, NAM indices and ozone anomalies present a correlation factor equal or greater than -0.5 as soon as we select the NAM indices to be greater than 0.5 in absolute value. At this stage of the data set, we still have 50 points. We observe a very similar behaviour over Iceland. Over Eastern US, a threshold of 0.8 in absolute value is necessary to get the correlation $(-0.65)$. However, it is important to note that NAM indices present extreme values mostly in winters-springs (Fig. 17) while maxima in ozone anomalies have been recorded the following springssummers (Fig. 10). Our method may be not ideal to reveal the complete correlation between NAM and ozone anomalies but exhibit a coherent behaviour between the stratospheric circulation and the ozone concentrations. This is beyond the scope of the paper to go further in finding explanations that should involve the different time scales of the stratospheric circulation along with the ozone production/destruction processes ones.

\section{Summary and discussion}

The availability of the altitude of different iso-PV surfaces along each measurement of the MOZAIC flights allowed us to build a new set of ozone climatologies presenting

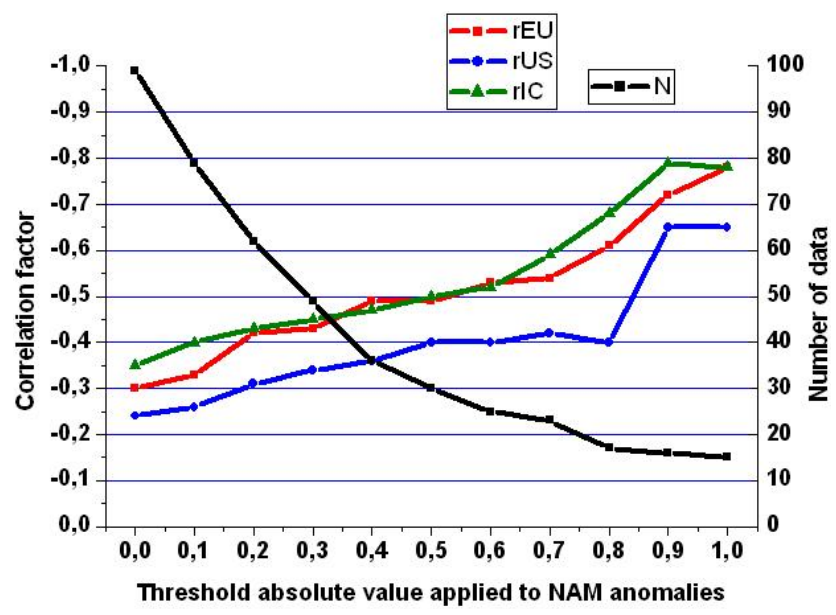

Fig. 18. Summary of the different correlation factor obtained for the three selected region (rEU, rUS and rIC) when applying different thresholds in absolute value to the NAM indices along with the number of months remaining in the data set $(\mathrm{N})$.

the ozone data recorded at flight altitude, with reference to the tropopause altitude. The tropopause is defined as being a transition zone $30 \mathrm{hPa}$ thick centered on the surface $P V=2$ pvu. Two other layers are defined on either side of the tropopause to encompass all the cruise levels of the MOZAIC flights. Then, we have access to the upper tropospheric and lower stratospheric ozone distributions independently of any ozone threshold and regardless of the seasonal variations of the tropopause. The tropospheric distributions appear zonally and meridionally homogenous while the stratospheric distributions exhibit a meridional gradient characteristic of both the "lowermost stratosphere" and the "tropically controlled transition region" as defined earlier by Rosenlof et al. (1997). In the upper troposphere, we observe a clear summer maximum with values from 40 to $80 \mathrm{ppbv}$ and there is no vertical gradient. In the lower stratosphere, concentrations from 150 to $500 \mathrm{ppbv}$ maximize in spring and we observe a strong vertical gradient between our two defined pressure intervals in the LS. This new presentation of the data gives new possibilities for 3-D models, and future satellite data validation. This climatology will be of particular interest for all the studies dealing with the tropopause region and the variability of ozone observed there (retrieval of the tropospheric columns, mass fluxes from the stratosphere, etc.). Further more, this new set of ozone distributions issued from the MOZAIC program has the great advantage to be characteristic of the state of the atmosphere where aircraft emissions occur. With this new set of data, it has been possible to calculate the fraction of time that commercial airliners reside within the lower stratosphere as detailed by Forster et al. (2003).

The most interesting result constructing this new ozone climatology is probably the first assessment of the ozone 
variability in this most critical UTLS region. Over the North Atlantic, 9 years (1994-2003) of regular ozone measurements show an increase rate of about $1 \% / y r$ in the UT and about $1.5 \% / y r$ in the LS. This large and surprising interannual variability is partly attributed to a so-called 19981999 anomaly exhibiting a deviation 10 to $15 \%$ from the climatological mean (which correspond to +8 or $+50 \mathrm{ppbv}$ in the UT and in the LS respectiveley). This anomaly is observed in the whole UTLS region, independently of the altitude (i.e. independently of the location of the tropopause, independently of the definition of the tropopause). This anomaly has been also observed in other measurement datasets and it has been established that it mostly concerns regions from 500 to $100 \mathrm{hPa}$. This last statement is of particular interest as it shows that upper troposphere and lower stratosphere are somehow "more coupled" than previously thought. Understanding the origin and evolution of ozone in the UTLS requires taking into account the different aspects of the troposphere-stratosphere system in its global scale if possible. As a first stage, photochemical and dynamical causes have been investigated such as increased boreal and tropical fires, increased STE, and a maximum in the NAO index. For example the year 1998 corresponds to strong biomass burning events over Siberia and North Canada following the intense tropical events from 1997 because of El-Nino. Globally, 1998 and 1999 are considered as extreme years from many perspectives. No clear and obvious causal explanation for the high ozone records can be drawn right now. However, we think it could probably be attributed to variations in large scale dynamics, through wave-driven stratospheric circulation influencing down to the middle and upper troposphere. The strong correlations with the atmopsheric teleconnections indices (NAO and NAM; Figs. 15, 17, 18) and the recent analysis from Zeng and Pyle (2005) both argue in this favor. This latter study demonstrate that ENSO affects global total tropospheric ozone not only via its effects on chemical processes but also via its profound effect on STE in the extratropics. The relationship between the ozone concentration and the NAO (and ENSO) offers a fascinating interaction between different aspects of the climate system. Although the NAO is a natural mode of atmospheric variability, surface (ocean and land), stratospheric, or even anthropogenic processes may influence its phase and amplitude. "Much remains to be learned about the mechanisms that produce such low frequency changes in the North Atlantic climate, but it seems increasingly likely that human activities are playing a significant role" as said by Visbeck et al. (2000). More over, recent studies have shown that increase in greenhouse gases emissions may favor occurrences of positive phases for the NAO (Cassou et al., 2004; Terray et al., 2004). Then, our consideration for the 1998 anomaly in $\mathrm{CO}$ and $\mathrm{CH}_{4}$ to explain the ozone maximum in the UT and the correlation with the NAO index are maybe not independent phenomenon as previously thought.
The additional ozone anomalies in the LS especially noticeable over Europe in springs-summers 2001 and 2002 seem anti-correlated to the NAM index. Thus the ozone variability in the LS appears to be linked to anomalies in the large-scale circulation patterns that propagate downward from the upper stratosphere to the UTLS.

Finally, this study re-emphasizes the need of long-term measurements. The climatology issued from the first two years of measurements has been very useful for the 3-D models improvement. Nevertheless, both the chemistry and the transport in the UTLS have to be analyzed and understood to go a step further in assessing the ozone budgets and trends in the UTLS region and attribute them to various forcing. This analysis highlights the coupling between the troposphere, (at least the upper one) and the stratosphere (at least the lower one). That gives a strong argument for the urgent need of validated stratosphere/troposphere coupled chemical and transport models. Successful modeling of the inter-annual variability discussed here would provide a key test of these models and hence improve our understanding of the complex chemical and dynamical mechanisms that control the concentration and budget of ozone in this most critical UTLS region.

Acknowledgements. The authors acknowledge for their strong support the European Communities, EADS Airbus and the airlines (Air France, Lufthansa, Austrian Airlines, and former Sabena) who carry free of charge the MOZAIC equipment and perform the maintenance. We warmly thank A. Marenco, former MOZAIC coordinator, now retired from atmospheric sciences but deeply involved in the fight against cystic fibrosis diseases contracted by children. We thank M. Baldwin for providing the NAM data.

Edited by: P. Haynes

\section{References}

Appenzeller, C., Weiss, A. K., and Staehelin, J.: North Atlantic Oscillation modulates total ozone winter trends, Geophys. Res. Lett., 27 , 1131-1134, 2000.

Baldwin M. P. and Dunkerton, T. J.: Stratospheric harbingers of anomalous weather regimes, Science, vol. 294, 2001.

Bethan, S., Vaughan, G., and Reid, S. J.: A comparison of ozone and thermal tropopause heights and the impact of tropopause definition on quantifying the ozone content of the troposphere, Q. J. R. Meteorol. Soc., 122, 929-944, 1996.

Bronnimann, S., Luterbacher, J., Schmutz, C., Wanner, H., and Staehelin, J.: Variability of total ozone at Arosa, Switzerland, since 1931 related to atmospheric circulation indices, Geophys. Res. Lett., 27, 2213-2216, 2000.

Brunner, D., Staehelin, J., Jeker, D., Wernli, H., and Schumann, U.: Nitrogen oxides and ozone in the tropopause region of the Northern Hemisphere: Measurements from commercial aircraft in 1995/1996 and 1997, J. Geophys. Res., 106, 27 673-27 699, 2001.

Cassou, C.: Du changement climatique aux régimes de temps: l'oscillation nord-atlantique, La Météorologie, May 2004. 
Danielsen, E. F.: Stratosphere-troposphere exchange based on radioactivity, ozone, and potential vorticity, J. Atmos. Sci., 25, 502-518, 1968.

Cooper O. R., Stohl, A., Eckhardt, S., Parrish, D. D., Oltmans, S. J., Johnson, B. J., Nédélec, P., Schmidlin, F. J., Newchurch, M. J., Kondo, Y., and Kita, K.: A springtime comparison of tropospheric ozone and transport pathways on the east and west coasts of the United States, J. Geophys. Res., 110, D05S90, doi:10.1029/2004JD005183, 2005.

Dlugokencky, E. J., Walter, B. P., Masarie, K. A., Lang, P. M., and Kasischke, E. S.: Measurements of an anomalous global methane increase during 1998, Geophys. Res. Lett., 28, 499-502, 2001.

Emmons, L. K., Hauglustaine, D. A., Muller, J. F., Caroll, M. A., Brasseur, G. P., Brunner, D., Staehelin, J., Thouret, V., and Marenco, A.: Data composites of airborne observations of tropospheric ozone and its precursors, J. Geophys. Res., 105, $20497-$ $20538,2000$.

Fischer, H., Wienhold, F. G., Hoor, P., Bujok, O., Schiller, C., Siegmund, P., Ambaum, M., Scheeren, H. A., and Lelieveld, J.: Tracer correlations in the northern high latitude lowermost stratosphere: Influence of cross-tropopause mass exchange, Geophys. Res. Lett., 27 , 97-100, 2000.

Forster, C., Stohl, A., James, P., and Thouret, V.: The residence times of aircraft emissions in the stratosphere using a mean emissions inventory and emissions along flight tracks, J. Geophys. Res., 108(D12), 8524, doi:10.1029/2002JD002515, 2003.

Galanter, M., Levy, H., and Carmichael, G. R.: Impacts of biomass burning on tropospheric CO, NOx and O3, J. Geophys. Res., 105, 6633-6653, 2000.

Gouget, H., Vaughan, G., and Marenco, A.: Decay of a cut-off low and contribution to stratosphere-troposphere exchange, Q. J. R. Meteorol. Soc., 126, 1117-1142, 2000.

Hoerling, M. P., Schaack, T. D., and Lenzen, A. J.: Global objective tropopause analysis, Mon. Wea. Rev., 119, 1816-1831, 1991.

Hoinka, K. P.: Statistics of the global tropopause pressure, Mon. Wea. Rev., 26, 23 113-23 131, 1998.

Holton, J. R., Haynes, P. H., McIntyre, M. E., Douglas, A. R., Rood, R. B., and Pfister, L.: Stratosphere-troposphere exchange, Rev. Geophys., 33, 403-439, 1995.

Hood, L. L., Rossi, S., and Beulen, M.: Trends in lower stratospheric zonal winds, Rossby wave breaking behaviour, and column ozone at northern mid-latitudes, J. Geophys. Res., 104, 24321-24339, 1999.

Hoor, P., Gurk, C., Brunner, D., Hegglin, M. I., Wernli, H., and Fischer, H.: Seasonality and extent of extratropical TST derived from in-situ measurements during SPURT, Atmos. Chem. Phys., 4, 1427-1442, 2004.

Hoor, P., Fischer, H., and Lelieveld, J.: Tropical and extratropical tropospheric air in the lowermost stratosphere over Europe: a CO-based budget, Geophys. Res.Lett., 32, L07802, doi:10.1029/2004GL022018, 2005.

Hoskins, B. J., McIntyre, M. E., and Robertson, A. W.: On the use and significance of isentropic potential vorticity maps, Q. J. R. Meteorol. Soc., 111, 877-946, 1985.

Hurrell, J. W.: Decadal trends in the North Atlantic Oscillation regional temperatures and precipitation, Science, 269, 676-679, 1995.

Law, K. S., Plantevin, P. H., Shallcross, D. E., Rogers, H. L., Pyle, J. A., Grouhel, C., Thouret, V., and Marenco, A.: Evaluation of modelled O3 using MOZAIC data, J. Geophys. Res., 103, 23 721-23 737, 1998.

Law, K. S., Plantevin, P.-H., Thouret, V., Marenco, A., et al.: Comparison between global chemistry transport model results and measurements of ozone and water vapour by airbus in-service aircraft (MOZAIC), J. Geophys. Res., 105, 1503-1525, 2000.

Li, Q., Jacob, D. J., Logan, J. A., Bey, I., et al.: A tropospheric ozone maximum over the Middle East, Geophys. Res. Lett., 28, 3235-3238, 2001.

Logan, J. A.: An analysis of ozonesonde data for the troposphere: Recommendations for testing 3-D models and development of a gridded climatology for tropospheric ozone, J. Geophys. Res., 104, 16 115-16 149, 1999.

Marenco, A., Thouret, V., Nédélec, P., Smith, H. G., et al.: Measurement of ozone and water vapor by Airbus in-service aircraft: The MOZAIC airborne program, An overview, J. Geophys. Res., 103, 25 631-25 642, 1998.

Martin, R. V., Jacob, D. J., Logan, J. A., Bey, I., et al.: Global model analysis of TOMS and in-situ observations of tropical tropospheric ozone, J. Geophys. Res., 107(D18), 4351, doi:10.1029/2001JD001480, 2002.

Morgenstern, O. and Carver, G. D.: Quantification of filaments penetrating the subtropical barrier, J. Geophys. Res., 104, $31275-$ $31286,1999$.

Morgenstern, O. and Marenco, A.: Wintertime ozone climatology of MOZAIC ozone based upon the pv-ozone-analogy, J. Geophys. Res., 105, 15 481-15 493, 2000.

Nikulin, G. N. and Repinskaya, R. P.: Modulation of total ozone anomalies in the mid-latitude Northern Hemisphere by the Artic Oscillation, Izvestiya Atmospheric and Oceanic Physics, 37, 633-643, 2001.

Ovarlez, J., van Velthoven, P., and Schlager, H.: Water vapor measurements from the troposphere to the lowermost stratosphere: Some signatures of troposphere to stratosphere exchanges, J. Geophys. Res., 104, 16 973-16978, 1999.

Pan L. L., Randel, W. J., Gary, B. L., Mahomey, M. J., and Hintsa, E. J.: Definitions and sharpness of the extratropical tropopause: A trace gas perspective, J. Geophys. Res., 109, D23103, doi:10.1029/2004JD004982, 2004.

Perlwitz, J. and Graf, H.-F.: The statistical connection between tropospheric and stratospheric circulation of the Northern Hemisphere in winter, J. Climate, 8, 2281-2295, 1995.

Rao, T. N., Kirkwood, S., Arvelius, J., von der Gathen, P., and Kivi, R.: Climatology of UTLS ozone and the ratio of ozone and potential vorticity over northern Europe, J. Geophys. Res., 108(D22), 4703, doi:10.1029/2003JD003860, 2003.

Rinsland, C. P., Mahieu, E., Zander, R., Demoulin, P., Forrer, J., and Buchmann, B.: Free tropospheric CO, C2H6, and HCN above central Europe: Recent measurements from the Jungfraujoch station including the detection of elevated columns during 1998, J. Geophys. Res., 105, 24 235-24 249, 2000.

Rosenlof, K. H., Tuck, A. F., Kelly, K. K., Russel, J. M., and McCormick, M. P.: Hemispheric asymmetries in water vapour and inferences about transport in the lower stratosphere, J. Geophys. Res., 102, 13 213-13 234, 1997.

Sauvage, B., Thouret, V., Cammas, J. P., Gheusi, F., Athier, G., and Nédélec, P.: Tropospheric ozone over Equatorial Africa: regional aspects from the MOZAIC data, Atmos. Chem. Phys., 5, 311$335,2005$. 
Schumann, U., Schlager, H., Arnold, F., Ovarlez, J., et al.: Pollution from aircraft emissions in the North Atlantic flight corridor: Overview on the POLINAT projects, J. Geophys. Res., 105, 3605-3631, 2000.

Scott, R. K., Cammas, J. P., Mascart, P., and Stolle, C.: Stratospheric filamentation into the upper tropical troposphere, J. Geophys. Res., 106, 11 835-11 848, 2001.

Seo, K.-H. and Bowman, K. P.: A climatology of isentropic crosstropopause exchange, J. Geophys. Res., 106, 28 159-28 172, 2001.

Shapiro M. A., Wernli, H., Bond, N. A., and Langland, R.: the influence of the 1997-99 El-Nino Southern Oscillation on extratropical baroclinic life cycles over the Eastern North Pacific, Q. J. R. Meteorol. Soc., 127, 331-342, 2001.

Stohl, A., James, P., Forster, C., Spichtinger, N., Marenco, A., Thouret, V., and Smit, H. G. J.: An extension of MOZAIC ozone climatologies using trajectory statistics, J. Geophys. Res., 106, 27 757-27 768, 2001.

Spichtinger, N., Damoah, R., Eckhardt, S., Forster, C., James, P., Beirle, S., Marbach, T., Wagner, T., Novelli, P. C., and Stohl, A.: Boreal forest fires in 1997 and 1998: a seasonal comparison using transportmodel simulations and measurements data, Atmos. Chem. Phys. 4, 1857-1868, 2004.

Tarasick, D. W., Fioletov, V. E., Wardle, D. I., Kerr, J. B., and Davies, J.: Changes in the vertical distribution of ozone over Canada from ozonesondes: 1980-2001, J. Geophys. Res., 110, D02304, doi:10.1029/2004JD004643, 2005.

Terray, L., Demory, M. E., Déqué, M., de Coetlogon, G., and Maisonnave, E.: Simulation of the late twenty-first century changes in wintertime atmospheric circulation over Europe due to anthropogenic causes, J. Clim. Lett., 17(24), 4630-4635, 2004.

Thouret, V., Marenco, A., Nédélec, P., and Grouhel, C.: Ozone climatologies at $9-12 \mathrm{~km}$ altitude as seen by the MOZAIC airborne program between September 1994 and August 1996, J. Geophys. Res., 103, 25 653-25 679, 1998a.

Thouret, V., Marenco, A., Logan, J., Nédélec, P., and Grouhel, C.: Comparisons of ozone measurements from the MOZAIC airborne program and the ozone sounding network at eight locations, J. Geophys. Res., 103, 25 695-25 720, 1998b.
Visbeck, M. H., Hurrell, J. W., Polvani, L., and Cullen, H. M.: The North Atlantic Oscillation: Past, present, and future, summary of a session presented at the 12th annual symposium on Frontiers of Science, held 2-4 November 2000 at the Arnold and Mabel Beckman Center of the National Academies of Science and Engineering in Irvine, CA., 2000.

Wallace, J. M. and Thompson, D. W. J.: Annular modes and climate prediction, Physics Today, February, 28-33, 2002.

Wirth, V.: Thermal versus dynamical tropopause in upper tropospheric balanced flow anomalies, Q. J. R. Meteorol. Soc., 126, 299-317, 2000.

World Meteorological Organization: Atmospheric Ozone 1985, WMO Bulletin Vol. 16, World Meteorological Organization, 1957.

World Meteorological Organization: Scientific assessment of ozone depletion: 1998, WMO rep.41, Geneva, p. chap. 7, 1999.

Wotawa, G., Novelli, P. C., Trainer, M., and Granier, C.: Interannual variability of summertime $\mathrm{CO}$ concentrations in the Northern Hemisphere explained by boreal forest fires in North America and Russia, Geophys. Res. Lett., 28 , 4575-4578, 2001.

Zahn, A., Neubert, R., Maiss, M., and Platt, U.: Fate of long-lived trace species near the Northern Hemisphere tropopause: Carbon dioxide, methane, ozone, and sulfur hexafluoride, J. Geophys. Res., 104, 13 923-13 942, 1999.

Zahn, A., Brenninkmeijer, C. A. M., and van Velthoven, P. F. J.: Passenger Aircraft CARIBIC, 1997-202, part I: the extratropical chemical tropopause, Atmos. Chem. Phys. Discuss., 4, 10911117, 2004.

Zbinden, R., Cammas, J.-P., Thouret, V., Nédélec, P., Karcher, F., and Simon, P.: Mid-latitude Tropospheric Ozone Columns from the MOZAIC program: climatology and interannual variability, Atmos. Chem. Phys., 6, 1053-1073, 2006.

Zeng, G. and Pyle, J. A.: Influence of El Nino Southern Oscillation on stratosphere/troposphere exchange and the global tropospheric ozone budget, Geophys. Res. Lett., 32, L01814, doi:10.1029/2004GL021353, 2005. 